\title{
Structural and Functional Diversity of CLAVATA3/ESR (CLE)-Like Genes from the Potato Cyst Nematode Globodera rostochiensis
}

\author{
Shun-Wen Lu, ${ }^{1}$ Shiyan Chen, ${ }^{1}$ Jianying Wang, ${ }^{2}$ Hang Yu, ${ }^{1}$ Demosthenis Chronis, ${ }^{1}$ Melissa G. Mitchum, ${ }^{2}$ \\ and Xiaohong Wang ${ }^{1,3}$ \\ 'Department of Plant Pathology and Plant-Microbe Biology, Cornell University, Ithaca, NY 14853, U.S.A.; ${ }^{2}$ Interdisciplinary \\ Plant Group, Division of Plant Sciences and Bond Life Sciences Center, University of Missouri, Columbia 65211, U.S.A.; \\ ${ }^{3}$ United States Department of Agriculture-Agricultural Research Service (USDA-ARS), Robert W. Holley Center \\ for Agriculture and Health, Ithaca, NY 14853, U.S.A.
}

Submitted 10 December 2008. Accepted 11 May 2009.

Plant CLAVATA3/ESR-related (CLE) peptides have diverse roles in plant growth and development. Here, we report the isolation and functional characterization of five new $C L E$ genes from the potato cyst nematode Globodera rostochiensis. Unlike typical plant CLE peptides that contain a single CLE motif, four of the five Gr-CLE genes encode CLE proteins with multiple CLE motifs. These $G r-C L E$ genes were found to be specifically expressed within the dorsal esophageal gland cell of nematode parasitic stages, suggesting a role for their encoded proteins in plant parasitism. Overexpression phenotypes of $G r-C L E$ genes in Arabidopsis mimicked those of plant $C L E$ genes, and Gr-CLE proteins could rescue the Arabidopsis clv3-2 mutant phenotype when expressed within meristems. A short root phenotype was observed when synthetic GrCLE peptides were exogenously applied to roots of Arabidopsis or potato similar to the overexpression of $G r-C L E$ genes in Arabidopsis and potato hairy roots. These results reveal that $G$. rostochiensis CLE proteins with either single or multiple CLE motifs function similarly to plant CLE proteins and that CLE signaling components are conserved in both Arabidopsis and potato roots. Furthermore, our results provide evidence to suggest that the evolution of multiple CLE motifs may be an important mechanism for generating functional diversity in nematode CLE proteins to facilitate parasitism.

S.-W. Lu and S. Chen contributed equally to this work and are joint first authors.

Corresponding author: X. Wang; E-mail: xiaohong.wang@ars.usda.gov or xw57@cornell.edu; Telephone: +1 607255 3518; Fax: +1 6072551132.

Present address of S.-W. Lu: USDA-ARS, Cereal Crops Research Unit, Northern Crop Science Laboratory, Fargo, ND 58105-5677, U.S.A.

Nucleotide sequence data are available in the National Center for Biotechnology Information database under the following accession numbers: $\mathrm{Gr}$ $C L E-1$ cDNA clone (EU386829), Gr-CLE-1 genomic clone (EU386830), $G r-C L E-4-A$ cDNA clone (EU386833), Gr-CLE-4-A genomic clone (EU386840), Gr-CLE-4-B cDNA clone (EU386834), Gr-CLE-4-B genomic clone (EU386841), Gr-CLE-4-C cDNA clone (EU386836), $G r-$ $C L E-4-C$ gnomic clone (EU386843), $G r-C L E-4-D$ cDNA clone (EU386837), and Gr-CLE-4-D genomic clone (EU386844).

* The $\boldsymbol{e}$-Xtra logo stands for "electronic extra" and indicates that two supplemental tables and four supplemental figures are published online. Figure 3 also appears in color online.
Potato cyst nematodes (Globodera rostochiensis and G. pallida) are obligate root parasites that have evolved highly sophisticated parasitic relationships with specific host plants (Davis et al. 2004; Hussey and Grundler 1998). Infective second-stage juveniles (J2) hatch from eggs within the cyst in the soil and infect host roots. The $\mathrm{J} 2$ uses its stylet (hollow mouth spear) to aid its intracellular root migration and selects an initial cell within root tissues for the development of a complex feeding structure called a syncytium (Dropkin 1969; Jones 1981). Juveniles of $G$. rostochiensis preferentially select a fully differentiated cortical cell in potato roots to initiate a syncytium (Jones and Northcote 1972). At the onset of feeding, the nematode becomes sedentary and relies on the syncytium for nourishment for the remainder of its life cycle.

The formation of the syncytium represents one of the most complicated plant responses triggered by plant pathogens. The syncytium is a highly metabolically active multinucleate structure formed by extensive cell wall dissolution of neighboring cells around the initial syncytial cell. Its characteristics include enlarged nuclei and nucleoli, dense cytoplasm, increased numbers of subcellular organelles, small vacuoles, and thickened cell walls with elaborate wall ingrowths formed adjacent to the vascular tissues (Jones 1981). The formation of wall ingrowths facilitates nutrient uptake from the xylem into the syncytium to meet the demands of the feeding nematode. Some of these developmental characteristics are features of various types of plant cells, including meristematic cells and transfer cells, suggesting that cyst nematodes have likely evolved mechanisms to manipulate plant developmental pathways to form a novel cell type (Mitchum et al. 2008).

Secreted proteins encoded by parasitism genes expressed within the single dorsal and two subventral esophageal gland cells of cyst nematodes represent the major functional molecules that directly or indirectly modulate plant cellular processes involved in the induction, formation, and maintenance of the syncytium (Davis et al. 2004, 2008; Hussey 1989). Interestingly, parasitism genes from the soybean cyst nematode (Heterodera glycines) encoding small secreted proteins with similarity to CLAVATA3/ESR-related (CLE) signaling peptides were identified previously (Gao et al. 2003; Olsen and Skriver 2003; Wang et al. 2001). This is the only known report of $C L E$ genes outside the plant kingdom. Plant CLE genes encode small proteins with an N-terminal signal peptide, a variable domain, and a conserved 14-amino-acid (aa) domain called the CLE motif located at or near their $\mathrm{C}$ termini (Cock and 
McCormick 2001). Plant CLE proteins have been suggested to have roles in shoot, floral, and root meristem maintenance, organ size regulation, apical dominance, and vascular development (Casamitjana-Martinez et al. 2003; Fiers et al. 2004, 2005; Hirakawa et al. 2008; Hobe et al. 2003; Ito et al. 2006; Strabala et al. 2006). To date, more than 100 putative CLE genes have been identified from diverse plant species (Oelkers et al. 2008). Sequence alignments among plant CLE proteins reveal little sequence similarity outside their conserved CLE domains and mounting evidence implicates the conserved CLE domain as the major functional domain of CLE proteins (Fiers et al. 2005, 2006; Ito et al. 2006; Kondo et al. 2006; Ni and Clark 2006). More recently, plant CLE genes that encode multiple tandem C-terminal CLE motifs (Kinoshita et al. 2007; Oelkers et al. 2008) have been identified, although the biological significance of the repeated CLE motifs and the function of this novel class of plant $C L E$ genes are yet to be discovered.

The Arabidopsis genome contains $32 C L E$ genes that encode CLE proteins with a single CLE motif located at or near their $\mathrm{C}$ termini (Cock and McCormick 2001). The founding member, CLAVATA3 (CLV3), functions as a peptide ligand that interacts with the CLV1/CLV2 receptor complex to signal a stem-cell-restricting pathway in shoot and floral meristems (Fletcher et al. 1999). CLV1, expressed in the central zone of the shoot apical meristem (SAM), encodes a membrane-bound leucine-rich repeat receptor-like kinase (LRR-RLK) (Clark et al. 1997). CLV2, having a much broader expression pattern than that of $C L V 1$, encodes an LRR receptor-like protein lacking a kinase domain (Jeong et al. 1999). The functional form of CLV3 is a 12-aa peptide derived from its CLE domain (Kondo et al. 2006). The physical interaction between the dodeca-CLV3 peptide and the LRR domain of CLV1 was also demonstrated (Ogawa et al. 2008). More recently, it was revealed that CORYNE (CRN), a novel receptor kinase, is a new component of the CLV3 signaling pathway in Arabidopsis (Muller et al. 2008). The Arabidopsis WUSCHEL (WUS) gene, which encodes a homeodomain transcription factor, is also an important regulator that promotes stem cell identity in the SAM (Laux et al. 1996; Mayer et al. 1998). WUS is a key target of the CLV signaling pathway, and a negative regulatory feedback loop between WUS and CLV genes controls the size of the stem cell population in the SAM (Brand et al. 2000; Schoof et al. 2000). Mutations in any of the $C L V$ genes result in enlarged shoot and floral meristems due to the uncontrolled proliferation of stem cells (Clark et al. 1993, 1995; Fletcher et al. 1999; Kayes and Clark 1998), whereas CLV3 overexpression or mutation of the WUS gene terminates SAM development (Brand et al. 2000; Laux et al. 1996).

Surprisingly, overexpression of an $H$. glycines $C L E$ gene (Hg-4G12) in Arabidopsis caused premature termination of the SAM similar to CLV3 (Davis 2009; Wang et al. 2005). In addition, the nematode CLE was able to rescue the Arabidopsis clv3-1 mutant phenotype when expressed under the control of the Cauliflower mosaic virus (CaMV) $35 \mathrm{~S}$ promoter (Wang et al. 2005). These results suggested that nematode and plant CLE peptides share functional similarity and led to the hypothesis that ligand mimicry of plant CLE signaling peptides may be an important mechanism in cyst nematode parasitism of host plants (Mitchum et al. 2008; Wang et al. 2005).

Here, we report the identification and functional characterization of five $C L E$-like genes from $G$. rostochiensis. Interestingly, unlike $H$. glycines $C L E$ genes, four of the five $G r-C L E$ genes were found to encode secreted proteins with multiple CLE motifs at their C termini. Based on structure and sequence similarities, $G r-C L E$ genes were grouped into two classes: $G r-$ $C L E-1$ and $G r-C L E-4$. These $G r-C L E$ genes were found to be exclusively expressed within the dorsal esophageal gland cell of nematode parasitic stages, indicating a potential role for these nematode-secreted CLE proteins in plant parasitism. We also conducted detailed functional characterization of these Gr-CLE genes. Results from our in vitro and in planta studies demonstrate clearly that $G$. rostochiensis CLE proteins with either single or multiple CLE motifs can function as ligand mimics of plant CLE signaling peptides. Additionally, our indepth functional characterization provides evidence to suggest that the evolution of multiple CLE motifs may be an important mechanism for generating functional diversity in CLE proteins to facilitate nematode parasitism. Furthermore, the discovery of $C L E$ genes from a different genus of cyst nematodes signifies the importance of ligand mimicry as a mechanism for plant parasitism by this group of nematodes.

\section{RESULTS}

\section{G. rostochiensis $C L E$-like genes encode secreted proteins containing multiple CLE motifs.}

We used the $H$. glycines CLE protein sequences (Gao et al. 2003; Wang et al. 2001) to search the NematodeNet database and identified a homolog from $G$. rostochiensis that was subsequently named $G r-C L E-1$. The full-length cDNA sequence of Gr-CLE- 1 was further obtained by $5^{\prime}$ and $3^{\prime}$ rapid amplification of cDNA ends (RACE) cloning and found to encode a predicted protein of 204 aa that contained a putative N-terminal signal peptide (Fig. 1A) analyzed by the SignalP program (Nielsen et al. 1997). Interestingly, unlike $H$. glycines CLE peptides that contain only one C-terminal CLE motif, Gr-CLE-1 was found to contain four putative CLE motifs at its C terminus (Fig. 1A); this unique structure, which is absent from the 32-member Arabidopsis CLE family, has only been identified in a very few putative CLE peptides from rice and other plant species (Kinoshita et al. 2007; Oelkers et al. 2008). The last motif (GrCLE1-2, RVTPGVPDRQHR) was dissimilar to the first three identical CLE motifs (GrCLE1-1, RVTPGGPDP LHN). Within the conserved 12-aa CLE motifs of plant CLE peptides, residues at positions $1,4,6,7,8,9,11$, and 12 are highly conserved (Oelkers et al. 2008). The GrCLE1-2 motif contained four residue differences at positions $6,9,10$, and 12 as compared with GrCLE1-1 (Fig. 1B). Only two putative plant CLE motifs of $A t$ CLE43 and Pc CLE178 have an arginine residue instead of a conserved proline residue at position 9, and none of the plant CLE motifs identified has an arginine residue at position 12 (Oelkers et al. 2008). It is possible that GrCLE1-2 may not be a functional CLE motif. Noticeably, the last three motifs of Gr-CLE-1were each preceded by a 9-aa spacer (named GrCLE1-a and GrCLE1-b) containing seven to eight polar residues and one central hydrophobic residue (leucine) located 5 aa (designated as position -5) upstream of the first residue of the following 12-aa CLE motif (Fig. 1B). The 9-aa sequence (GrCLE1-a') preceding the first GrCLE1-1 motif was divergent from the other spacers but retained a hydrophobic residue (tyrosine) at the -5 position (Fig. 1B). The variable domain between the signal peptide and the start of the first GrCLE1-1 motif had little sequence similarity to known proteins in the databases and was only approximately $27 \%$ identical to those of $H$. glycines CLE peptides.

The corresponding genomic sequence of $G r-C L E-1$ was obtained by polymerase chain reaction (PCR) using primers designed according to the cDNA sequence. The genomic clone of Gr-CLE-1 was revealed to contain two introns (Fig. 1A) similar to that observed in CLV3 (Fig. 1A) and At CLE4O genes (Fletcher et al. 1999; Hobe et al. 2003).

Further analysis of approximately 100 cDNA clones obtained by reverse-transcription (RT)-PCR using messenger (m)RNA isolated from preparasitic $\mathrm{J} 2$ or nematode-infected root materi- 
als identified four additional $C L E$-like genes. Although variations existed, these CLE-like genes were 90 to $99 \%$ identical to each other and only 72 to $78 \%$ identical to Gr-CLE-1. Therefore, these four $C L E$-like genes were grouped into a separate class from $G r-C L E-1$ and, subsequently, designated as Gr-CLE-4-A, Gr-CLE-4-B, Gr-CLE-4-C, and Gr-CLE-4-D (Fig. 1A). In addition, our cloning and sequence analysis showed that the relative abundance of the mRNA transcripts of $G r-C L E-4$ genes varied significantly, with $G r-C L E-4-B$ and Gr-CLE-4-C representing the most abundant transcripts in both preparasitic and parasitic stages of the nematode. How- ever, transcripts of $G r-C L E-4-A$ and $G r-C L E-4-D$ were found only in the preparasitic $\mathrm{J} 2$ and parasitic stages, respectively, revealing a low expression of $G r-C L E-4-A$ and $G r-C L E-4-D$ in certain stages of nematode development. The deduced GrCLE-4 proteins also contained an N-terminal signal peptide, a variable domain, and a $\mathrm{C}$-terminal region that contained either single or multiple CLE motifs (Fig. 1A). The variable domains of Gr-CLE-4 proteins were 65 to $67 \%$ identical to that of $\mathrm{Gr}$ CLE- 1 and only 24 to $27 \%$ identical to those of $H$. glycines CLE proteins. All Gr-CLE-4 proteins except Gr-CLE-4-C had either four or five tandem CLE motifs at their $\mathrm{C}$ termini with

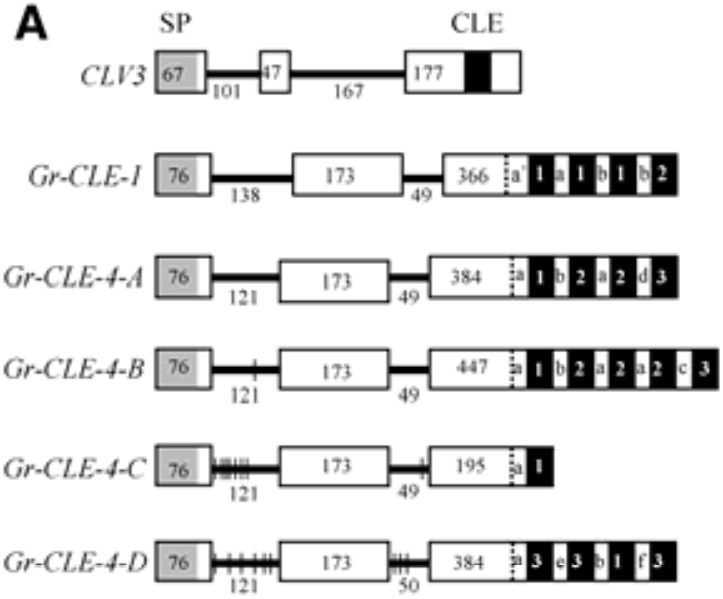

B

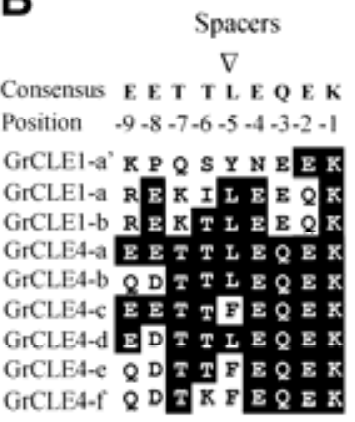

CLE motifs

R V S P G G P D P , H H

123456789101112

GrCLE1-1 R V $=$ P G G P D P I G

GrCLE1-2 R V T P G V P D R Q A R GrCLE4-1 R V A G A G P D P I H GrCLE4-2 R A V P A G P D P K B H GrCLE4-3 R G A P A G P D P I I B Hg-4G12 R I S P S G P D P B B : CLV3 R T V P S G P D P L H E At CLEI R L S P G G P D P R B H Ar CLE6 R V S P G G P D P Q B B

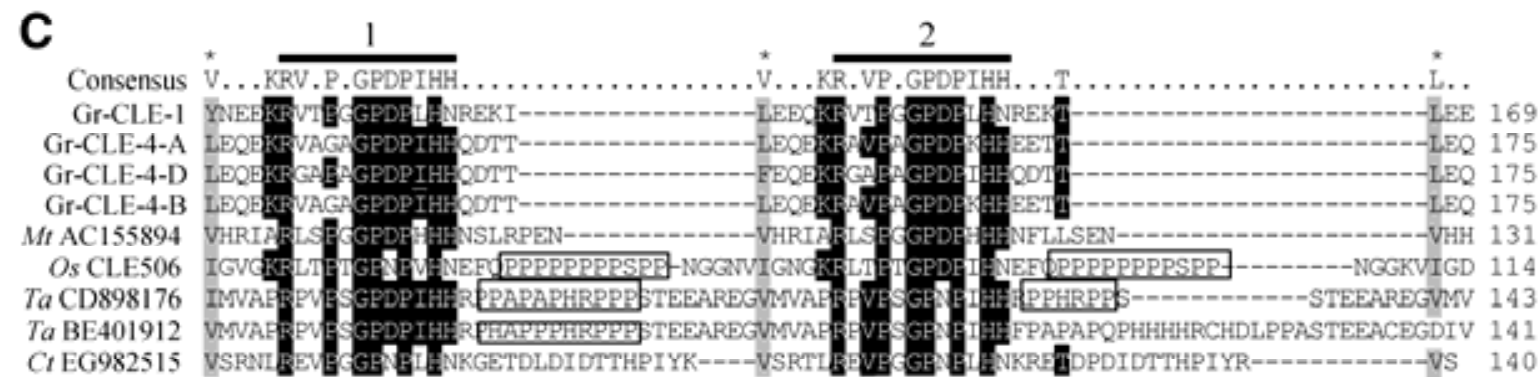

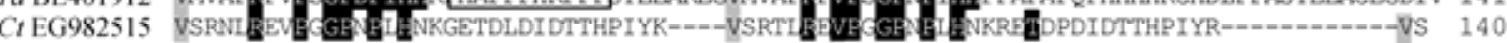
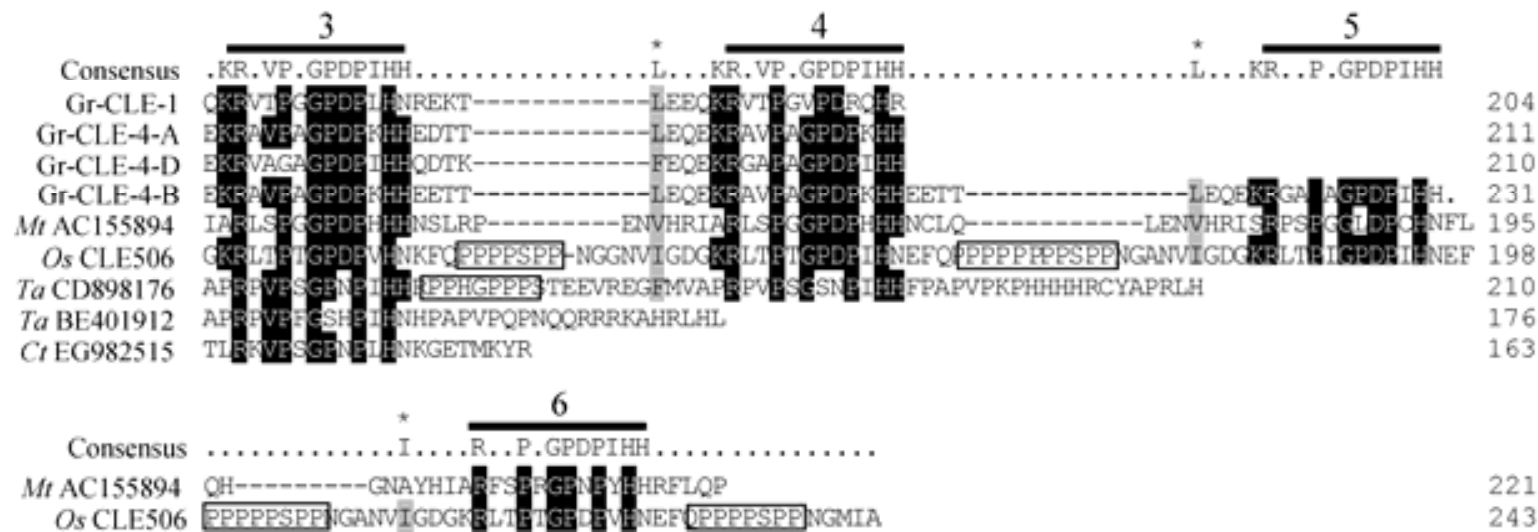

Fig. 1. Structure of Globodera rostochiensis CLAVATA3/ESR-related ( Gr-CLE) genes and relationship between nematode and plant CLE proteins. A, Organization of $G r$-CLE genes (drawn to scale) in comparison with CLV3. Exons and introns are indicated by boxes and solid lines, respectively. Numbers inside the boxes and below the lines indicate sizes (in base pairs) of exons and introns. Vertical lines indicate nucleotide differences in introns of $G r$-CLE-4 genes compared with Gr-CLE-4-A. Gray boxes in the first exons indicate signal peptide (SP) and the black boxes in the last exons indicate the 12-amino-acid (aa) CLE motifs. The numbers inside the black boxes and the letters in front of the black boxes indicate different CLE motifs and spacer sequences, respectively. B, Alignments of GrCLE spacer sequences (left) and the putative 12-aa CLE domains of nematode and related Arabidopsis CLE proteins (right). Residues identical to those in the consensus sequences are shaded in black. The numbers above each alignment indicate positions relative to the first residue of the 12 aa CLE motif. The conserved hydrophobic residue at the -5 position is indicated by a triangle. C, C-terminal sequence alignment of Gr-CLE and plant CLE proteins with multiple CLE motifs. Residues identical to those in the consensus sequence are shaded in black. The -5 position relative to each CLE motif is indicated by an asterisk and each hydrophobic residue at the position is shaded in gray. Each CLE motif is numbered and marked by a thick line above the alignment. Proline-rich sequences are boxed. GenBank accession numbers for CLE proteins from Heterodera glycines (Hg), Arabidopsis thaliana (At), Medicago truncatula (Mt), Oryza sativa (Os), Triticum aestivum (Ta), and Cyamopsis tetragonoloba $(\mathrm{Ct})$ are given in Supplementary Table 2 online. 
the potential to produce three different 12-aa CLE peptides (Fig. 1A and B) if proteolytically processed in vivo as suggested for plant CLE proteins (Ito et al. 2006; Kondo et al. 2006; Ni and Clark 2006). Similar to Gr-CLE-1, the CLE motifs of Gr-CLE-4-A, Gr-CLE-4-B, and Gr-CLE-4-D were each preceded by a 9-aa conserved spacer (named GrCLE4-a through GrCLE4-f) that contained a hydrophobic residue (leucine or phenylalanine) at the -5 position (Fig. 1B). The 9-aa sequences (GrCLE4-a) preceding the first CLE motif of each Gr-CLE-4 protein were identical. Interestingly, the hydrophobic nature of the residue at the -5 position was relatively conserved in plant CLE proteins that contain multiple CLE motifs (Fig. 1C) as well as in plant CLE proteins containing a single CLE motif (Supplementary Fig. 1).

All $G r$-CLE-4 genes contained two introns (Fig. 1A). The second introns among $G r-C L E-4$ genes were almost identical whereas their first introns were relatively polymorphic (Fig. 1A). The genomic clones of $G r-C L E-4$ genes were only approximately $73 \%$ identical to that of $G r-C L E-1$.

\section{Gr-CLE proteins contain a putative Src homology 3} interaction domain sequence in their variable domains.

Plant CLE proteins have very little sequence similarity except for the conserved C-terminal CLE domain. However, the amino acid alignment of nematode CLE proteins showed a conserved proline-rich region in their variable domains (Fig. 2A). Interestingly, proline-rich sequences were also found in the spacer regions of several plant CLE proteins that contain multiple CLE motifs (Fig. 1C). Proline-rich sequences may interact with proline recognition domains, including the Src homology 3 (SH3), WW, EVH1, and GYF domains, to mediate diverse intracellular signaling processes (Hou et al. 2006; Zarrinpar et al. 2003). The SH3 domain is probably the bestcharacterized structural unit found in numerous signaling pro- teins and they often recognize proline-rich peptides with the conserved core motif of PXXP ( $\mathrm{P}$ represents proline and $\mathrm{X}$ represents any amino acid) that forms a left-handed polyproline type-II helix (Zarrinpar et al. 2003). By using the SH3Hunter (Ferraro et al. 2007), a web server for predicting putative $\mathrm{SH} 3$ domain interaction sites on protein sequences, we found that the proline-rich sequences present in the variable domains of nematode CLE proteins, except Gr-CLE-1, may resemble SH3 ligands that contain the PXXP core motif (Fig. 2A). Putative $\mathrm{SH} 3$ domain interaction sequences containing the PXXP core motif were also identified in the variable domains of several plant CLE proteins (Fig. 2B).

\section{$G r-C L E$ genes are gland specific and}

differentially expressed throughout the nematode life cycle.

We used in situ mRNA hybridization to determine the spatial expression pattern of $G r-C L E$ genes in nematode specimens. Hybridization results using a $G r$-CLE-4 probe that could also potentially recognize $G r-C L E-1$ showed a strong hybridization signal specifically within the dorsal esophageal gland cell of parasitic stages of the nematode (Fig. 3A). A very weak hybridization signal was also detected within the dorsal gland cell of parasitic nematodes using a $G r$-CLE- 1 -specific cDNA probe (Supplementary Fig. 2). The presence of a putative signal peptide and the gland-specific expression suggest a role for $\mathrm{Gr}$ CLE proteins in plant parasitism. We further used TaqMan quantitative (q)RT-PCR to determine the expression profiles of $G r-C L E-1$ and $G r-C L E-4$ genes throughout the nematode life cycle. Infected roots that contained nematodes at different developmental stages were used as parasitic nematode materials for qRT-PCR analysis. $G r-C L E-1$ and $G r-C L E-4$ genes were revealed to have different expression patterns, although both of them were found to be upregulated in nematode parasitic stages (Fig. 3B). In the early parasitic stages (e.g., at 2, 5, and
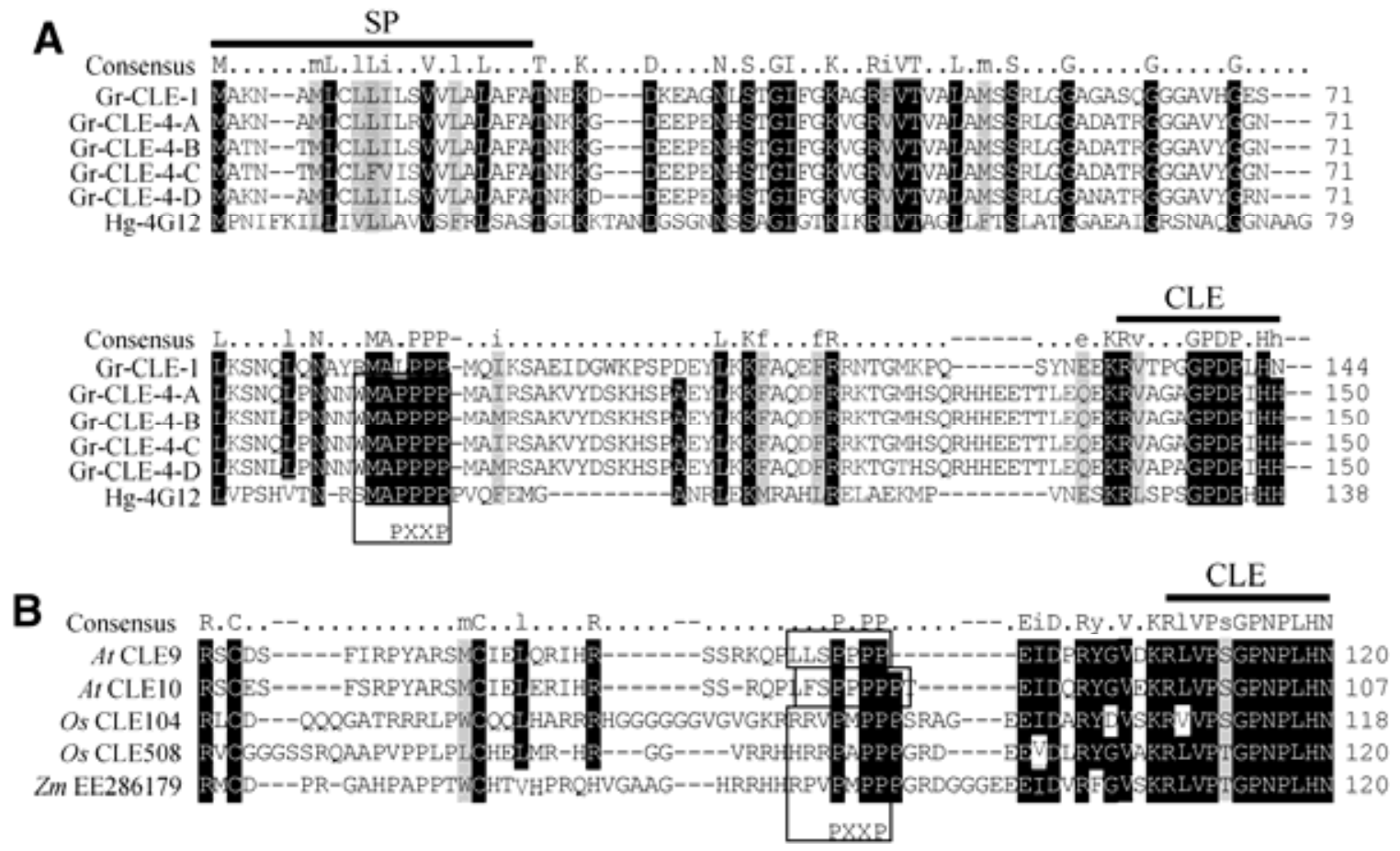

Fig. 2. Alignment of nematode and plant CLAVATA3/ESR-related (CLE) proteins containing the putative Src homology 3 (SH3) domain interaction sequence in the variable domain. A, N-terminal sequence alignment of nematode CLE proteins. Amino acid residues corresponding to positions 1 to 144 of Globodera rostochiensis CLE-1 (Gr-CLE-1) are shown. B, Alignment of partial sequences of plant CLE proteins. Residues corresponding to positions 49 to 107 of At CLE10 are shown. In A and B, residues identical or similar to those in the consensus sequences are shaded in black and gray, respectively. The putative SH3 domain interaction sequences are boxed and marked with the PXXP core motif. The signal peptide (SP) sequence and the 12-amino-acid CLE motif are indicated by thick lines above the alignment. GenBank accession numbers for CLE proteins from Heterodera glycines (Hg), Arabidopsis thaliana (At), Oryza sativa (Os), and Zea mays ( $\mathrm{Zm})$ are given in Supplementary Table 2 online. 
10 days postinoculation [dpi]), transcripts of Gr-CLE-1 increased gradually and reached the highest level at $10 \mathrm{dpi}$; an eightfold increase in expression compared with the preparasitic J2 stage. Gr-CLE-4 had a much higher expression level than $G r$-CLE- 1 throughout the parasitic stages. Compared with preparasitic J2, transcripts of $G r$-CLE-4 had a 200- to 500-fold increase in the early parasitic stages ( 5 and $10 \mathrm{dpi}$ ) and a more than 1,200-fold increase at $21 \mathrm{dpi}$. Because the $G r$-CLE-4 TaqMan probe could recognize all of the $G r-C L E-4$ genes, it is not clear whether the difference in expression level is related to a difference in gene copy number between the two classes of $G r-C L E$ genes or is a reflection of a difference in promoter activities of $G r-C L E-1$ and $G r-C L E-4$ genes. The expression of both $G r-C L E-1$ and $G r-C L E-4$ genes was low in the preparasitic life stages, including egg and preparasitic J2 (Fig. 3B).

\section{Synthetic GrCLE peptides cause short root phenotypes in Arabidopsis and potato.}

Mounting evidence supports the idea that the conserved CLE motif represents the major functional domain of plant CLE proteins. Gr-CLE genes encode four potential 12-aa CLE motifs (Fig. 1A). To examine the functional sufficiency of these nematode CLE motifs, we conducted in vitro root assays (Fiers et al. 2005) using synthetic dodecapeptides (GrCLE1-112p, GrCLE4-1-12p, GrCLE4-2-12p, and GrCLE4-3-12p) corresponding to the four CLE motifs of Gr-CLE proteins. A 16aa peptide (Ag-16p) (Fiers et al. 2005) corresponding to the $C$ terminus of AGAMOUS that has no similarity with plant CLE motifs and a 12-aa CLV3 peptide (CLV3-12p) were used as negative and positive controls, respectively. In addition, several peptides, including a mutated GrCLE1-1 dodecapeptide (GrCLE1-1m-12p, with a Gly-to-Ala conversion as in clv3-1 and clv3-5 mutants), a 14-aa GrCLE1-1 peptide (GrCLE1-1$14 \mathrm{p}$, with one additional $\mathrm{N}$-terminal and one additional C-terminal residues compared with Gr-CLE1-1-12p), and three 13aa peptides of GrCLE4-1-13p, GrCLE4-2-13p, and GrCLE43-13p (all contained an extra N-terminal lysine residue compared with the corresponding dodecapeptides), were synthesized and used in the in vitro root assays.

Seed of Arabidopsis and potato, nonhost and host of G. rostochiensis, respectively, were germinated on vertical plates con- taining agar medium with $10 \mu \mathrm{M}$ of each peptide. The length of primary roots was measured over the course of the study. The CLV3-12p peptide severely suppressed root growth of both Arabidopsis (Fig. 4A) and potato (Fig. 4B) compared with the no-peptide or the Ag-16p-peptide treatment. As observed previously with the 14-aa CLV3 peptide (Fiers et al. 2005), Arabidopsis roots treated with CLV3-12p showed a phenotype of root meristem consumption (Fig. 4E) compared with the control roots (Fig. 4C and D). All of the dodecapeptides of GrCLE1-112p, GrCLE4-1-12p, Gr-CLE4-2-12p, and GrCLE4-3-12p suppressed root growth when applied exogenously to Arabidopsis and potato roots, but to varying degrees (Fig. 4A and B). GrCLE1-1-12p had a level of suppression comparable with CLV3-12p on both Arabidopsis and potato roots. However, the three dodecapeptides of GrCLE4 showed a lesser degree of root suppression compared with GrCLE1-1-12p, especially on potato roots. Interestingly, we found that the mutated GrCLE1-1m-12p peptide gave a level of suppression similar to GrCLE1-1-12p on both Arabidopsis (Fig. 4A) and potato roots (Fig. 4B). Consistent with the root phenotype observed for the CLV3 peptide treatment, Arabidopsis roots treated with GrCLE peptides also showed a phenotype of root meristem consumption; however, the degree of root meristem consumption was more severe for roots treated with GrCLE1-1-12p than for those treated with GrCLE4 peptides (Fig. 4F, G, and H).

A processed 12-aa CLE peptide has been suggested to interact with its plant receptor (Ito et al. 2006; Kondo et al. 2006; Ogawa et al. 2008); therefore, we investigated the potential functional forms of Gr-CLE proteins by examining the activity of synthetic peptides that contained extra residues in addition to the 12-aa CLE motifs. Surprisingly, GrCLE1-1-14p showed a level of activity similar to GrCLE1-1-12p on the suppression of both Arabidopsis and potato root growth (Fig. 4A and B). In contrast, the longer peptides of GrCLE4-1-13p, GrCLE4-2$13 p$, and GrCLE4-3-13p did not show activities on root suppression (Fig. 4A and B).

\section{Overexpression of $\mathrm{Gr}$-CLE genes in Arabidopsis} produces phenotypes resembling plant $C L E$ genes.

Arabidopsis CLE overexpression phenotypes have been characterized into distinct groups including i-a) aboveground
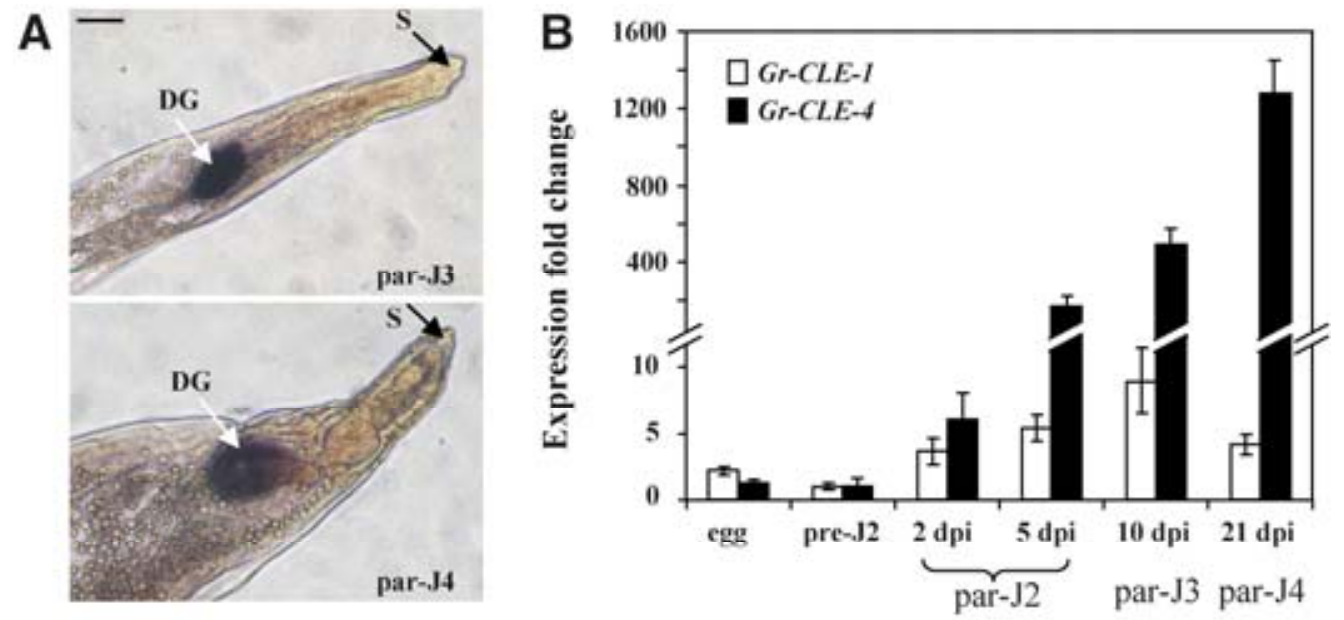

Developmental stages

Fig. 3. Spatial and developmental expression of Globodera rostochiensis CLAVATA3/ESR-related (Gr-CLE) genes. A, Hybridization (dark staining; indicated by an arrow) of a digoxygenin-labeled antisense $G r-C L E-4$ cDNA probe to messenger (m)RNA expressed exclusively within the dorsal gland cell (DG) of a parasitic third-stage juvenile (par-J3) (upper panel) and a parasitic fourth-stage juvenile (par-J4) (lower panel) of Globodera rostochiensis. Bar $=10 \mu \mathrm{m}$ and $\mathrm{S}=$ stylet. B, Developmental expression of $G r$-CLE genes throughout the nematode life cycle. Each column represents the mean of two independent experiments with the standard deviations of the mean, and each experiment contained three technical replicates for each mRNA sample. Tested stages included eggs, preparasitic secondstage juveniles (pre-J2), and parasitic J2s (par-J2s), par-J3s, and par-J4s within root tissues collected at 2, 5, 10, and 21 days postinoculation (dpi). 
wus phenotypes and short roots, i-b) aboveground wus phenotypes and long roots, ii) dwarf, iii) shrub-like, and iv) long root (Strabala et al. 2006). Overexpression of the H. glycines CLE gene, $H g-4 G 12$, in Arabidopsis produced phenotypes similar to Arabidopsis CLE genes that fall into the i-a subgroup which includes At CLE9, 10, 11, and 13 (Wang et al. 2005). Unlike H. glycines CLE proteins, Gr-CLE proteins, except Gr-CLE4-C, contained multiple CLE motifs. To gain insight into the potential function of Gr-CLE proteins in planta, we conducted overexpression studies in Arabidopsis, a nonhost for G. rostochiensis. In addition to discovering overexpression phenotypes, we wanted to determine the potential site of action of Gr-CLE proteins in vivo and to confirm the functional importance of nematode CLE domains. Therefore, for each $G r$-CLE gene, three different expression constructs were generated: full-length coding sequence, the coding sequence without the signal peptide, and the coding sequence lacking the CLE domain. Each gene was cloned behind the CaMV $35 S$ promoter, and the resulting construct (e.g., 35S:Gr-CLE-1, 35S:Gr-CLE-
1 $\triangle S P$, or 35S:Gr-CLE-1 $C C L E s$ ) was introduced into wild-type Arabidopsis. For each genotype, between 52 and 199 primary transgenic plants that were obtained from nine independent $\mathrm{T} 1$ pools were analyzed. Transgene expression was confirmed by RT-PCR. Because the $G r-C L E-4-A$ gene is very similar to the $G r-C L E-4-B$ gene, an overexpression study was not conducted for $G r-C L E-4-A$.

Of the 125 transgenic $35 S: G r-C L E-1$ plants examined, $100 \%$ produced a wus-like phenotype, in which the SAM ceased normal organ initiation after the generation of the first true leaves (Fig. 5B). These plants had much smaller rosette diameters at 14 days after germination (DAG) (Fig. 5B) compared with the empty-vector controls (Fig. 5A) and remained dwarf at later developmental stages (Fig. 5F and M). 35S:Gr-CLE-1 plants generally showed elevated anthocyanin accumulation (Fig. 5B, F, and M). In all, 49\% of the wus plants were not able to recover from the initial SAM arrest and died before they flowered (Table 1). The rest of the wus plants that survived produced abnormal flowers, some of which lacked carpels and
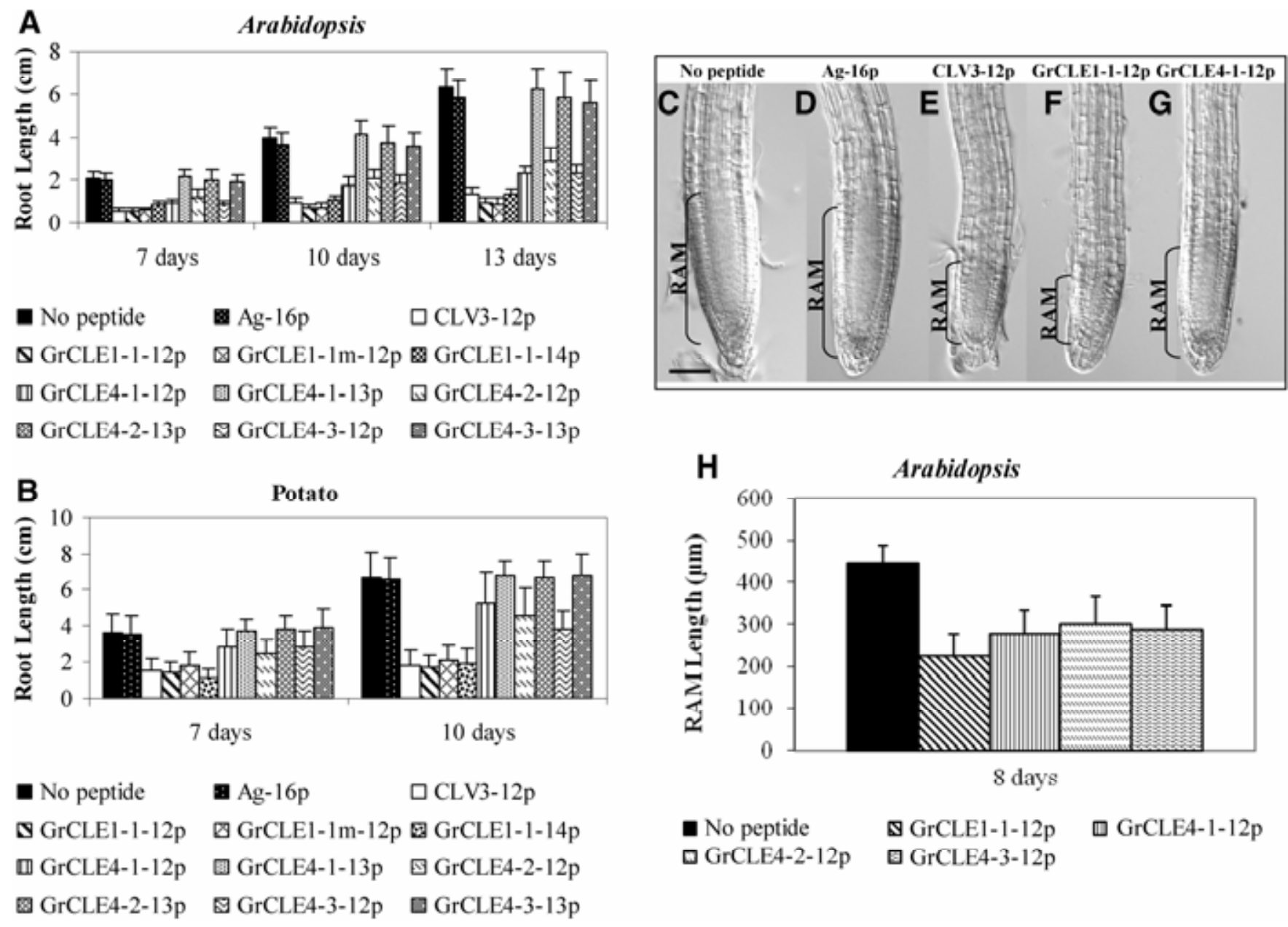

Fig. 4. Effects of synthetic CLAVATA3/ESR-related (CLE) peptides on root growth and root meristem. A and B, Effects of different CLE peptides on the root growth of Arabidopsis (Columbia-0) and potato. The lengths of the main Arabidopsis roots were measured at 7, 10, and 13 days of growth on media containing individual peptides and the lengths of the main potato roots were measured at 7 and 10 days of growth on peptide-containing media. At least 24 Arabidopsis roots and 20 potato roots were included in each peptide treatment. Data and error bars represent mean \pm standard deviation. Note that both Arabidopsis and potato roots treated with individual synthetic peptides of GrCLE1-1-12p, GrCLE1-1m-12p, GrCLE1-1-14p, GrCLE4-1-12p, GrCLE4-2$12 \mathrm{p}$, and GrCLE4-3-12p were significantly shorter than roots with no peptide treatment or roots treated with the Ag-16p peptide $(P<0.01, t$ test). Similar results were obtained from a second independent experiment. C, Microscopic observation of the morphology of the primary roots of Arabidopsis (Columbia0) 8 days after the treatment with different peptides. At least 10 roots treated with Ag-16p or CLV3-12p peptide and at least 18 roots under no-peptide treatment or treated with individual GrCLE peptides were microscopically examined. D, Consumption of Arabidopsis root meristem triggered by GrCLE peptides. The root apical meristem (RAM) regions of individual primary roots were measured microscopically. Note that the average size of root apical meristems of roots under no peptide treatment is significantly larger than those of root apical meristems of roots treated with GrCLE peptides $(P<0.001, t$ test $)$, revealing a consumption of root meristem in GrCLE peptide-treated roots. In addition, the average size of root apical meristems of GrCLE1-1-12p treated roots is significantly less than those of root apical meristems of GrCLE4-1-12p $(P<0.01, t$ test $)$, GrCLE4-2-12p $(P<0.001, t$ test $)$, and GrCLE4-3-12p $(P<$ $0.001, t$ test) -treated roots. $\mathbf{C}$ through $\mathbf{G}$, The region of the RAM is marked by a bracket; bar $=50 \mu \mathrm{m}$. 

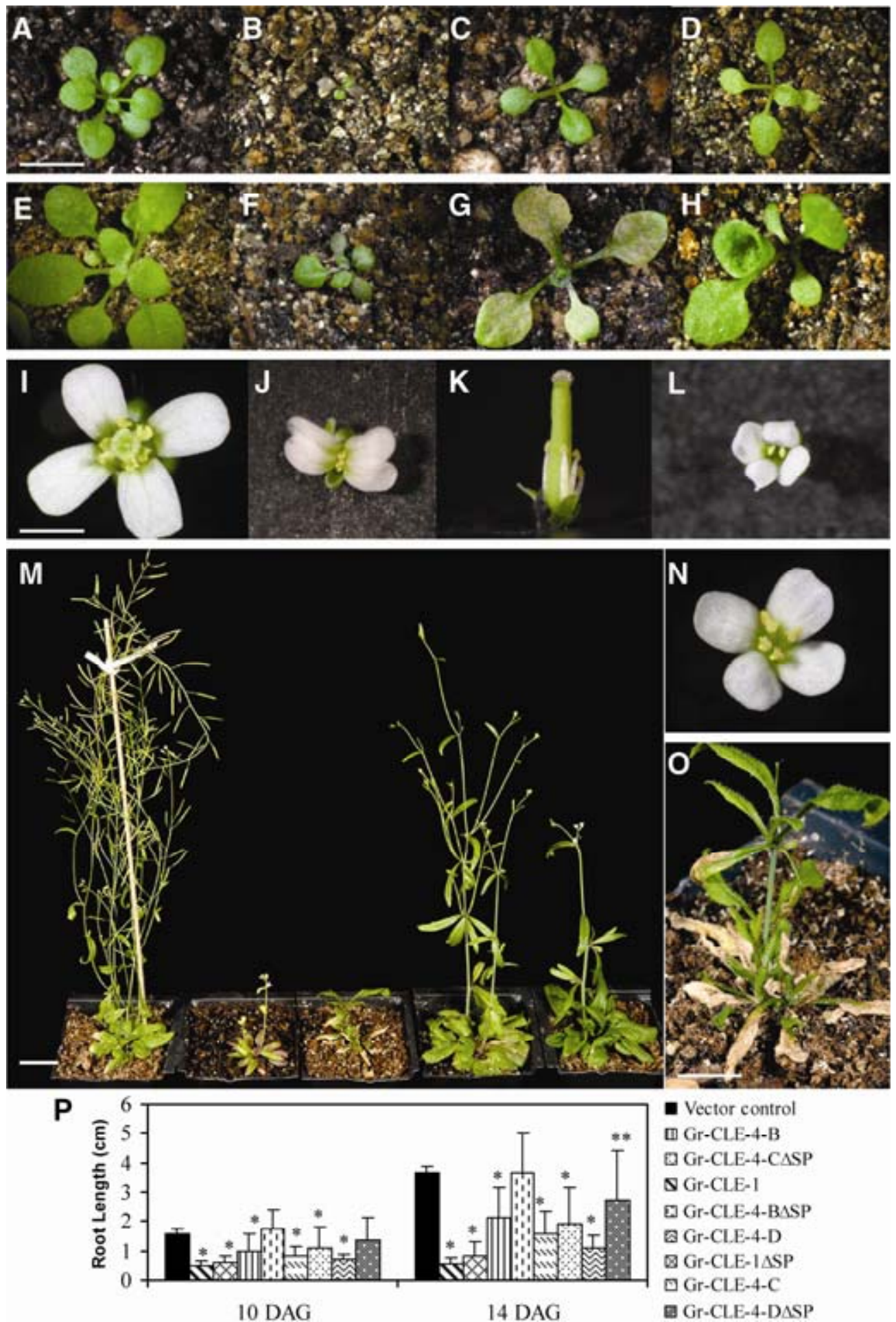

Fig. 5. Phenotypes of Arabidopsis (Columbia-0) transgenic plants overexpressing individual Globodera rostochiensis CLAVATA3/ESR-related (Gr-CLE) genes. A, Empty vector control plant 14 days after germination (DAG). B, 35S:Gr-CLE-1 plant at 14 DAG showing the suppression of the shoot apical meristem (SAM), anthocyanin accumulation, and dwarfism. C, 35S:Gr-CLE-4-B plant at 14 DAG showing the SAM arrest. D, 35S:Gr-CLE-4-D plant at 14 DAG showing the SAM arrest. E, Empty vector control plant at 21 DAG. F, 35S:Gr-CLE-1 plant at 21 DAG showing the SAM arrest, anthocyanin accumulation, and dwarfism. G, 35S:Gr-CLE-4-B plant at 21 DAG showing the SAM arrest and the symptom of leaf yellowing. H, 35S:Gr-CLE-4-D plant at 21 DAG showing the emergence of a trumpet-shaped leaf. I, Wild-type Arabidopsis flower containing four petals, six stamens, and two fused carpels. J, Flower of a 35S:Gr-CLE-1 plant showing a decreased number of stamens and no carpels, a phenotype similar to that of a wus flower. K, 35S:Gr-CLE-1 flower with sepals and petals removed showing the shorter stamens. L, 35S:Gr-CLE-4-B flower with two stamens and no carpels. M, Transgenic plants expressing the empty vector control, 35S:Gr-CLE-1,35S:Gr-CLE-4-B, 35S:Gr-CLE-4-C, and 35S:Gr-CLE-4-D, (from left to right) at 50 DAG. Note that 35S:Gr-CLE-4-C and 35S:Gr-CLE-4-D plants exhibit very similar phenotypes. N, Flower of a 35S:Gr-CLE-4-C plant with five stamens and no carpels. O, Enlarged photo showing the 35S:Gr-CLE-4-B plant in M. Note that the plant exhibits the symptom of leaf yellowing. Bar $=5 \mathrm{~mm}$ for A through $\mathrm{H}, 1 \mathrm{~mm}$ for I through $\mathrm{L}$ and $\mathrm{N}, 2 \mathrm{~cm}$ for $\mathrm{M}$, and $1 \mathrm{~cm}$ for $\mathrm{O}$. P, Lengths of the primary roots of transgenic Arabidopsis plants overexpressing individual Gr-CLE genes measured at 10 and 14 DAG. Between 36 and 70 roots of seedlings obtained from nine independent T1 pools for each genotype were analyzed. Note that the root lengths of all the transgenic lines except the 35S:Gr-CLE-4-B $\triangle S P$ line are significantly shorter than those of the vector control line $*^{*}$ and $* *=P<$ 0.0001 and $<0.001$, respectively, $t$ test). 
had a decreased number of stamens (similar to wus flowers) (Laux et al. 1996) (Fig. 5J) and some had shorter stamens (Fig. $5 \mathrm{~K}$ ) compared with wild-type flowers (Fig. 5I). Roots of transgenic 35S:Gr-CLE-1 plants were severely stunted (Fig. 5P), consistent with the short root phenotype of Arabidopsis roots treated exogenously with the GrCLE-1-1 peptides. In addition, under the long-day conditions used in the experiments, transgenic 35S:Gr-CLE-1 plants displayed delayed development, e.g., the average time to the first floral bud (stage 5.10) (Boyes et al. 2001) was 52 DAG compared with 24 DAG for the vector controls (Table 1).

Of the 169 transgenic 35S:Gr-CLE-1 $\triangle S P$ plants analyzed, only $29 \%$ displayed a wus-like phenotype (Table 1) and most of them produced normal flowers later on. The rest of the 35S:Gr-CLE-1 $\triangle S P$ plants showed no obvious aboveground phenotypes, although most of them had levels of transgene expression comparable to those of $35 S$ : $G r-C L E-1$ plants. Interestingly, 35S:Gr-CLE-1 $\triangle S P$ roots were also stunted compared with the vector controls (Fig. 6P); however, the degree of root stunting was less severe than that of $35 S: G r-C L E-1$ roots. Although transgene expression was confirmed, plants expressing 35S:Gr-CLE-1 $\triangle C L E S$ genes showed no obvious phenotypes (Table 1), indicating that the CLE motifs of Gr-CLE-1 were necessary for function.

In total, $100 \%$ of $35 S: G r-C L E-4-B$ transgenic plants also displayed wus-like phenotypes, including the suppression of
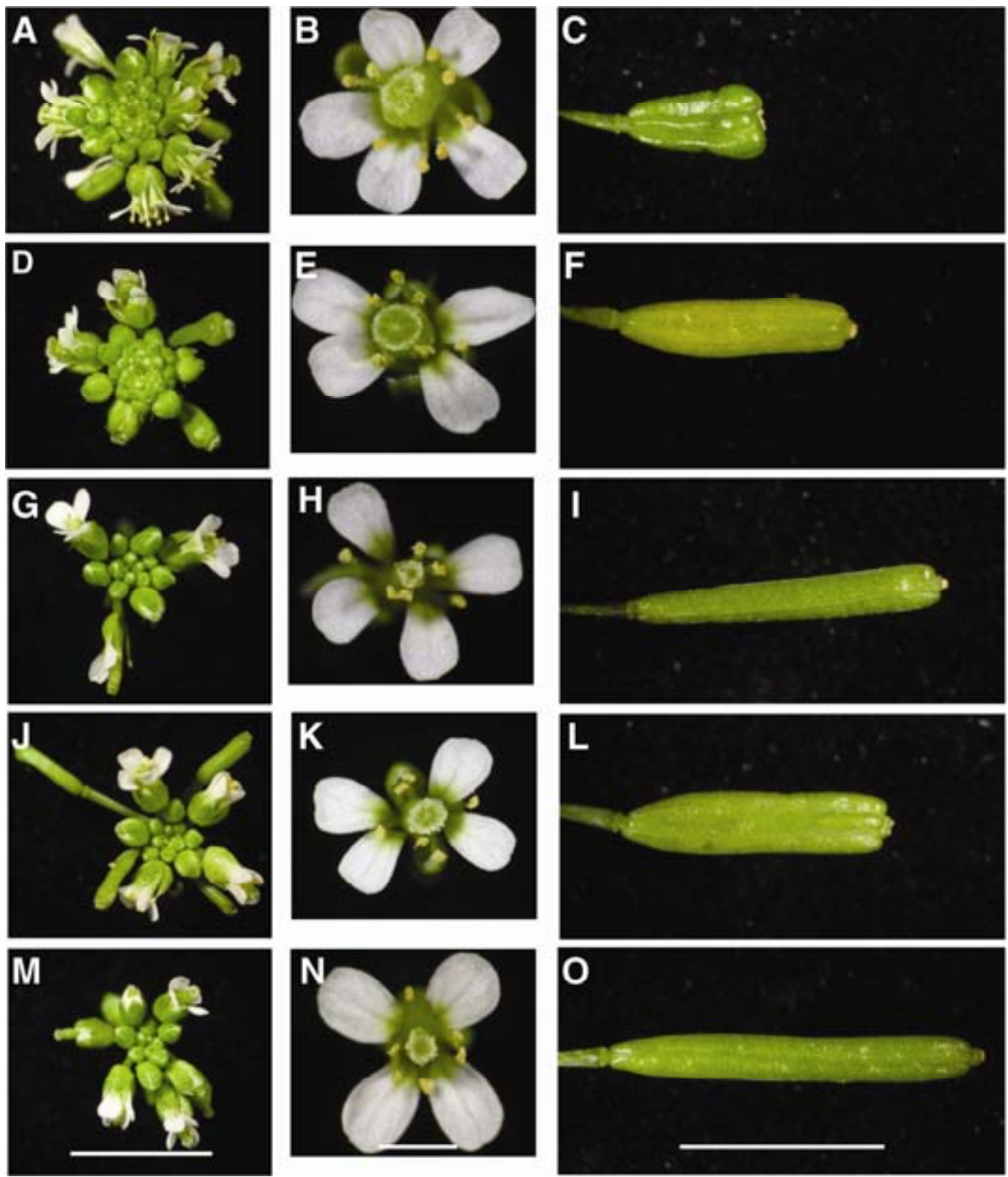

Fig. 6. Globodera rostochiensis CLAVATA3/ESR-related $(G r-C L E)$ genes provide partial or nearly complete rescue of $c l v 3-2$. A, Enlarged inflorescence of a $c l v 3$ 2 mutant. B, Flower of a $\operatorname{clv} 3-2$ mutant carrying more floral organs in each whorl. C, Silique of a $\operatorname{clv} 3-2$ mutant consisting of six to seven carpels. D, Inflorescence of a PCLV3:Gr-CLE-1/clv3-2 transgenic plant. Note that the size of the inflorescence is smaller than that of a $c l v 3-2$ mutant. E, Flower of a PCLV3:Gr$C L E-1 / c l v 3-2$ transgenic plant showing a partial restoration of wild-type floral organ numbers. F, Silique of a PCLV3:Gr-CLE-1/clv3-2 transgenic plant showing a phenotype and a carpel number different from those of a $c l v 3-2$ silique. G, Inflorescence of a PCLV3:Gr-CLE-4-B/clv3-2 transgenic plant showing a size similar to that of wild-type Arabidopsis. H, Flower of a PCLV3:Gr-CLE-4-B/clv3-2 transgenic plant showing a complete restoration of wild-type floral organ numbers. I, Silique of a PCLV3:Gr-CLE-4-B/clv3-2 transgenic plant consisting of two carpels. J, Inflorescence of a PCLV3:Gr-CLE-4-C/clv3-2 transgenic plant showing a size similar to that of wild-type Arabidopsis. K, Flower of a PCLV3:Gr-CLE-4-C/clv3-2 transgenic plant showing a partial restoration of wild-type floral organ numbers. L, Silique of a PCLV3:Gr-CLE-4-C/clv3-2 transgenic plant showing a phenotype and a carpel number different from those of a clv3-2 silique. M, Inflorescence of wild-type Arabidopsis (Landsberg erecta). N, Wild-type Arabidopsis flower consisting of four petals, six stamens, and two fused carpels. O, Silique of wild-type Arabidopsis consisting of two carpels. Bar $=5 \mathrm{~mm}$ for A, D, G, J, and M; $1 \mathrm{~mm}$ for B, E, H, K, and N; and $5 \mathrm{~mm}$ for C, F, I, L, and O. 
the SAM at an early developmental stage (Fig. 5C) and the production of wus flowers (Fig. 5L) later on. Most plants showed symptoms of leaf yellowing or plant death by 3 weeks after germination (Fig. 5G). In all, 73\% of the wus plants never recovered from the initial SAM arrest and died early (Table 1). Plants that did survive continued to show poor growth and symptoms of leaf yellowing (Fig. 5M and O). Unlike 35S:Gr$C L E-1$ overexpressing plants, $35 S: G r-C L E-4-B$ plants did not display dwarfism at early developmental stages and had no obvious anthocyanin accumulation (Fig. 5C and G). 35S:Gr$C L E-4-B$ roots exhibited a short root phenotype but the degree of root suppression was much less than that observed in 35S:Gr-CLE-1 roots (Fig. 5P). Similar to 35S:Gr-CLE-1 plants, 35S:Gr-CLE-4-B transgenic plants also displayed delayed development, having an average time to stage 5.10 at 50 DAG (Table 1). Overexpression phenotypes, including generation of wus seedlings, production of wus flowers, and developmental delay, were also observed in 35S:Gr-CLE-4-B $\triangle S P$ overexpressing plants (Table 1), but 35S:Gr-CLE-4-B $\triangle S P$ plants did not show an altered root growth (Fig. 5P). Levels of transgene expression were comparable between 35S:Gr-CLE4- $B$ and 35S:Gr-CLE-4-B $\triangle S P$ transgenic plants. In general, 35S:Gr-CLE-4-B $\triangle S P$ transgenic plants showed relatively milder phenotypes than those of $35 S: G r-C L E-4-B$ plants. As observed for 35S:Gr-CLE-1 $\triangle C L E S$ plants, 35S:Gr-CLE-4$B \triangle C L E$ s plants did not display obvious phenotypes (Table 1).

Comparable degrees of phenotypes were observed between 35:Gr-CLE-4-C and 35:Gr-CLE-4-C $\triangle S P$ transgenic plants and between 35S:Gr-CLE-4-D and 35S:Gr-CLE-4-D $\triangle S P$ transgenic plants. In general, $G r-C L E-4-C$ and $G r-C L E-4-D$ overexpressing plants exhibited very similar phenotypes, including generation of wus seedlings, production of wus flowers, developmental delay, and altered root growth (Fig. 5D, M, N, and P; Table 1). In addition, $G r-C L E-4-C$ and $G r-C L E-4-D$ plants often produced trumpet-shaped leaves (Fig. 5H). It is worth noting that, among all the transgenic lines tested, 35S:Gr-CLE-4-D plants displayed the most delayed development, having an average time of 58 DAG to reach stage 5.10 (Table 1). Consistent with the finding for Gr-CLE-1 and Gr-CLE-4-B proteins, the CLE motifs of Gr-CLE-4-C and Gr-CLE-4-D were necessary for function because no obvious phenotypes were observed in 35S:Gr-CLE-4-C $\triangle C L E$ and 35S:Gr-CLE-4-D $\triangle C L E S$ transgenic plants (Table 1).

All of the transgenic lines expressing individual full-length $G r$-CLE genes that showed wus-like phenotypes were found to have decreased levels of WUS expression in the SAM compared with the vector control lines (Supplementary Fig. 3), indicating a functional similarity of Gr-CLE proteins to CLV3.
Gr-CLE proteins can completely or partially replace CLV3 activity within meristems.

Several plant CLE proteins have been shown to be able to replace CLV3 function when expressed in the stem cell domain (Hobe et al. 2003; Ni and Clark 2006). Gr-CLE-1, Gr$C L E-4-B$, and $G r-C L E-4-C$ were the most representative $G r$ $C L E$ genes identified. To determine whether these genes could replace $C L V 3$ activity in the shoot and floral meristems, the full-length sequences of these three genes were cloned under the control of the CLV3 promoter and introduced into Arabidopsis clv3-2 mutant plants. The clv mutants have enlarged shoot and floral meristems that lead to shoot fasciation and formation of extra floral organs, including an increase in carpel number (Clark et al. 1993, 1995; Kayes and Clark 1998). For example, flowers of a clv3-2 mutant usually have six to seven carpels in the fourth whorl (Clark et al. 1995), whereas wild-type flowers have only two carpels in the fourth whorl. Carpel number is a sensitive measurement for meristem size (Clark et al. 1993; Ni and Clark 2006). Multiple independent transgenic lines for each transgene were obtained and analyzed (Table 2). Significantly, $G r-C L E-4-B$ was found to provide nearly complete rescue of the $\operatorname{clv} 3-2$ meristem defects, resulting in plants that displayed a size of the floral meristem (Fig. 6G) similar to that of wild-type Arabidopsis (Fig. 6M) and produced flowers (Fig. 6H) and siliques (Fig. 6I) that contained an average of two carpels, similar to those of wild-type Arabidopsis (Fig. 6N and O). Gr-CLE-1 and Gr-CLE-4-C genes provided partial rescue of $\operatorname{clv} 3-2$, resulting in plants that had a decreased size of the floral meristem (Fig. 6D and J) compared with that of $\operatorname{clv3-2}$ (Fig. 6A) and produced flowers (Fig. 6E and $\mathrm{K}$ ) and siliques (Fig. 6F and L) that contained a decreased number of carpels compared with those of $\operatorname{clv} 3-2$ (Fig. 6B and C). Together, these results indicate that Gr-CLE proteins can activate the CLV3 signaling pathway when expressed in the stem cell domain.

Table 2. Globodera rostochiensis CLAVATA3/ESR-related ( $G r$-CLE) genes provide partial or nearly complete rescue of $c l v 3-2$

\begin{tabular}{lccc}
\hline & \multicolumn{3}{c}{$\begin{array}{c}\text { No. of transgenic plants showing } \\
\text { rescue of the clv3-2 mutant }\end{array}$} \\
\cline { 2 - 4 } Construct & Partial & Nearly complete & No. analyzed \\
\hline PCLV3:Gr-CLE-1 & 4 & 0 & 6 \\
PCLV3:Gr-CLE-4-B & 0 & 21 & 21 \\
PCLV3:Gr-CLE-4-C & 8 & 0 & 8 \\
\hline
\end{tabular}

${ }^{a}$ Number of analyzed plants obtained from six to nine independent T1 pools.

Table 1. Summary of phenotypes of transgenic Arabidopsis plants overexpressing individual Globodera rostochiensis CLAVATA3/ESR-related (Gr-CLE) genes

\begin{tabular}{|c|c|c|c|c|c|c|c|}
\hline Construct & $\begin{array}{l}\text { No. of analyzed } \\
\text { T1 plants }\end{array}$ & $\begin{array}{c}\text { wus-Like } \\
(\%)\end{array}$ & $\begin{array}{c}\text { Dwarf } \\
(\%)\end{array}$ & Anthocyanin & $\begin{array}{c}\text { Mortality } \\
(\%)\end{array}$ & Flower phenotypes & $\begin{array}{l}\text { Time to stage } \\
5.10(\text { DAG) }\end{array}$ \\
\hline 35S:Gr-CLE-1 & 125 & 100 & 100 & Yes & 49 & $\begin{array}{l}\text { wus and those with } \\
\text { shorter stamens }\end{array}$ & 52 \\
\hline $35 S: G r-C L E-1 \triangle S P$ & 169 & 29 & 18 & No & 17 & Mostly wild type & 34 \\
\hline 35S:Gr-CLE-1 $\triangle C L E S$ & 131 & 0 & 0 & No & 1 & Wild type & 25 \\
\hline 35S:Gr-CLE-4-B & 85 & 100 & 0 & No & 73 & wus & 50 \\
\hline 35S:Gr-CLE-4-B $\triangle S P$ & 199 & 82 & 0 & No & 22 & wus and wild type & 35 \\
\hline 35S:Gr-CLE-4-BACLES & 136 & 0 & 0 & No & 2 & Wild type & 26 \\
\hline $35 S: G r-C L E-4-C$ & 81 & 98 & 0 & No & 21 & Mostly wus & 46 \\
\hline 35S:Gr-CLE-4-CASP & 65 & 92 & 0 & No & 7 & Mostly wus & 44 \\
\hline 35S:Gr-CLE-4-C $\triangle C L E$ & 52 & 0 & 0 & No & 13 & Wild type & 29 \\
\hline 35S:Gr-CLE-4-D & 188 & 100 & 0 & No & 3 & Mostly wus & 58 \\
\hline 35S:Gr-CLE-4-DASP & 216 & 98 & 0 & No & 2 & Mostly wus & 37 \\
\hline 35S:Gr-CLE-4D $\triangle C L E s$ & 78 & 0 & 0 & No & 9 & Wild type & 28 \\
\hline Empty vector control & 60 & 0 & 0 & No & 6 & Wild type & 24 \\
\hline
\end{tabular}

${ }^{\mathrm{a}} \mathrm{DAG}=$ days after germination. 
Overexpression of $G r$ - $C L E$ genes generates a short root phenotype in potato hairy roots.

A short root phenotype was observed when individual $G r$ $C L E$ genes were overexpressed in Arabidopsis, a nonhost of $G$. rostochiensis. To evaluate whether $G r-C L E$ genes could function similarly in potato, a host of $G$. rostochiensis, transgenic potato hairy roots overexpressing individual $G r-C L E$ genes were generated and analyzed. Similar to the effects in Arabidopsis, the overexpressed Gr-CLE-1, Gr-CLE-4-B, Gr-CLE-4$\mathrm{C}$, and Gr-CLE-4-D proteins could generate a short root phenotype in potato hairy roots (Fig. 7A). Furthermore, as observed in Arabidopsis roots, transgenic potato hairy roots overexpressing $G r-C L E-1$ were much shorter than those overexpressing individual $G r-C L E-4$ genes (Fig. 7A). A close examination of these short roots revealed a phenotype of root meristem consumption (Fig. 7C and D) because root hairs of these short roots were formed much closer to the tips than those of the control roots expressing only the empty vector (Fig. 7B). Transgene expression in potato hairy roots was confirmed by RTPCR analysis (Supplementary Fig. 4).

\section{DISCUSSION}

A common characteristic of the plant CLE family is that all members contain a conserved C-terminal CLE motif. The first non-plant $C L E$ genes isolated from $H$. glycines also encode a single CLE motif at their C termini (Gao et al. 2003; Olsen and Skriver 2003; Wang et al. 2001). Although several putative $C L E$ genes encoding multiple CLE motifs have recently been identified from several plant species (Cock and McCormick 2001; Kinoshita et al. 2007; Oelkers et al. 2008), the biological significance of the multiple CLE motifs and function of this novel class of plant CLE proteins are unknown. In this study, we found that four of the five $C L E$ genes identified from $G$. rostochiensis ( $G r-C L E)$ encode multiple CLE motifs that are evenly separated by relatively conserved spacer sequences. The $G r$-CLE genes encode four functional 12-aa CLE motifs that are organized in different combinations in Gr-CLE proteins, leading to a possibility of diversifying protein functions. Interestingly, our sequence analysis found that the residue at the -5 position upstream of the CLE motif in nematode and plant CLE proteins is usually hydrophobic. This residue may have an important role in CLE protein processing or function. Further sequence analysis identified a putative $\mathrm{SH} 3$ domain interaction site in the variable domain of nematode and several plant CLE proteins. SH3 domains are present in a variety of proteins and recognize proline-rich peptides to mediate diverse cellular processes, including signal transduction, cytoskeleton organization, and membrane trafficking (Cesareni et al. 2002; Zarrinpar et al. 2003). Plant CLE proteins have been suggested to be C-terminally processed to release a functional CLE peptide (Kondo et al. 2006; Ito et al. 2006; Ni and Clark 2006). Thus, it is worthwhile to determine whether nematode CLE proteins can be proteolytically processed in planta to release two functionally distinct peptides: a CLE ligand and a SH3 ligand. Although studies have indicated that the variable domain of CLV3 is dispensable for protein function (Fiers et al. 2006; Ni and Clark 2006), the identification of the conserved residues (Oelkers et al. 2008; this study) and the SH3 domain interaction site indicates a need to further elucidate the biological importance of the variable domain of CLE proteins.

Accumulating evidence suggests that the conserved CLE motif is the major functional domain of plant CLE proteins. In this study, we provide three lines of evidence that Gr-CLE proteins with either single or multiple CLE motifs can function as ligand mimics of endogenous plant CLE peptides. First, exogenous application of synthetic GrCLE peptides to Arabidopsis and potato roots generated a short root phenotype similar to that caused by CLV3 and other plant CLE peptide treatments. Second, overexpression of $G r$-CLE genes in Arabidopsis resulted in phenotypes closely resembling overexpression phenotypes reported for $A t$ CLE9, 10, 11, and 13 (Strabala et al. 2006). Third, we found that the overexpressed Gr-CLE proteins could partially or completely replace CLV3 function within meristems.

Like most Arabidopsis CLE peptides (Ito et al. 2006; Kinoshita et al. 2007), all of the synthetic GrCLE dodecapeptides suppressed Arabidopsis root growth in the in vitro root assay. It is worth mentioning that replacing the glycine residue at position 6 with alanine in the GrCLE1-1 peptide did not alter peptide activity, suggesting that, unlike its role in CLV3 (Fletcher et al. 1999), the glycine residue at position 6 may not be essential for nematode CLE peptide function. The GrCLE1-1 peptide caused a higher degree of root suppression in Arabidopsis than GrCLE4 peptides, and this was found to be consistent with the varying degrees of root suppression observed in Arabidopsis transgenic lines overexpressing Gr-CLE genes. Furthermore, the $G r-C L E-1$ overexpressing line showed phenotypic differences from those of $G r-C L E-4$ lines. Together, these results indicate that the Gr-CLE-1 protein or its processed peptide may signal through a receptor different from those of Gr-CLE-4-related peptides in Arabidopsis. It is intriguing that the longer peptide of GrCLE1-1-14p exhibited a level of root suppression activity comparable to that of GrCLE1-1$12 p$. Surprisingly, it was found that adding a single amino acid
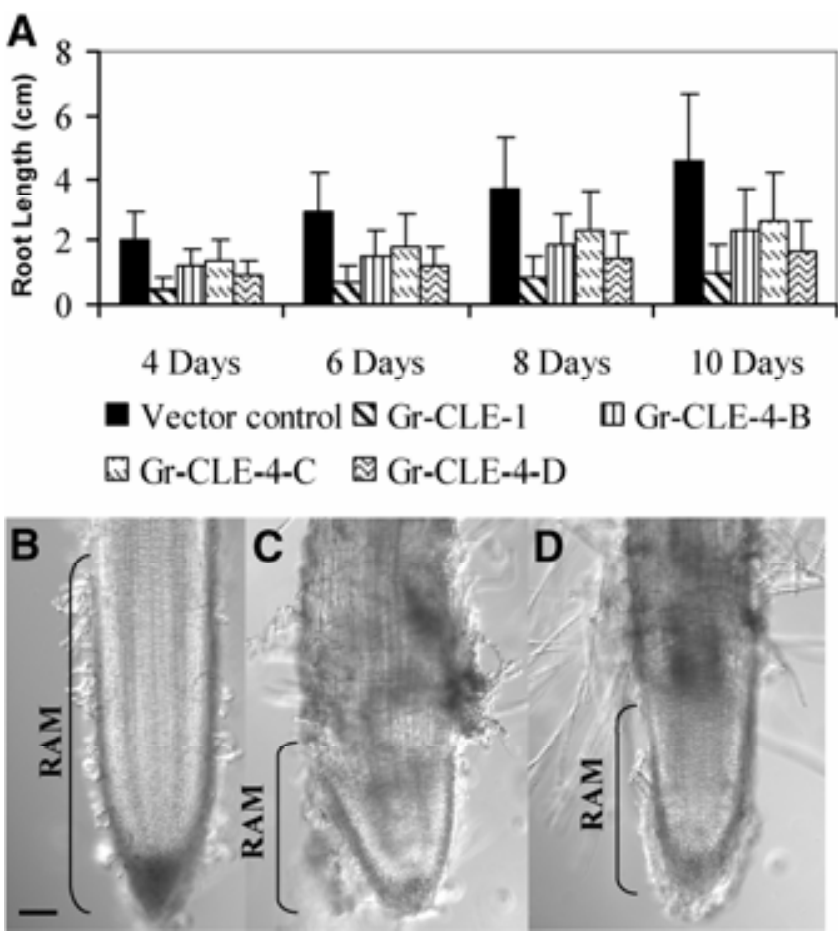

Fig. 7. Globodera rostochiensis CLAVATA3/ESR-related (Gr-CLE) gene overexpression in potato hairy roots. A, Lengths of the primary roots of each transgenic potato hairy root line measured at 4, 6, 8, and 10 days after dissecting from the initial transgenic roots. Between 60 and 133 independent transgenic roots for each genotype were analyzed. Data and error bars represent mean \pm standard deviation. Note that the root lengths of each transgenic line overexpressing individual $G r$-CLE genes are significantly shorter than those of the vector control line $(P<0.001, t$ test $)$. B, Morphology of an empty vector control root. C, Morphology of a $35 \mathrm{~S}: \mathrm{Gr}$ $C L E-1$ overexpressing hairy root showing the suppression of the root apical meristem (RAM) compared with the control root. D, Morphology of a 35S:Gr-CLE-4-D overexpressing hairy root showing the suppression of the RAM. B through D, Region of the RAM is marked by a bracket; bar = $50 \mu \mathrm{m}$. 
to the GrCLE4 dodecapeptides to make 13-aa peptides completely abolished peptide activities on root suppression. As suggested for plant CLE proteins, it is possible that the functional form of Gr-CLE-4 proteins may also be a dodecapeptide. However, considering that the in vitro root assay may not reflect in vivo activity of nematode CLE peptides and that it is still unclear whether all plant CLE proteins are processed in a manner similar to CLV3 and Zinnia TDIF (Ito et al. 2006; Kondo et al. 2006), further in vivo assays are necessary to elucidate the nature and mechanism of the proteolytic processing of Gr-CLE proteins.

It has been suggested that it is the processed CLE peptide that interacts with its cognate receptor to mediate signal transduction. Overexpression of Gr-CLE genes in Arabidopsis resulted in $w u s$-like seedlings, production of $w u s$ flowers, stunted roots, anthocyanin accumulation, delayed development, and death of young seedlings, many of which resembled overexpression phenotypes observed for Arabidopsis CLE proteins that contain only a single C-terminal CLE motif. Thus, our overexpression studies reveal that Gr-CLE proteins with either single or multiple CLE motifs can function similarly to plant CLE proteins and suggest that Gr-CLE proteins with multiple CLE motifs are proteolytically processed to release individual CLE peptides for function. Gr-CLE proteins have orderly arranged CLE motifs and they may become useful molecules for understanding the proteolytic processing of CLE proteins.

Many Arabidopsis CLE proteins are suggested to interact with similar receptors and play functionally redundant roles (Strabala et al. 2006). Transgenic Arabidopsis lines overexpressing $G r-C L E-4-C$ and $G r-C L E-4-D$ genes resulted in very similar phenotypes. Dodecapeptides of GrCLE4-1 and GrCLE4-3 differ in only two residues. It is likely that Gr-CLE-4-C and GrCLE-4-D or their potentially released GrCLE4-1 and GrCLE43 peptides may have redundant functions. Gr-CLE-4-B has the potential to release three different 12-aa CLE peptides, including GrCLE4-1, GrCLE4-2, and GrCLE4-3. The GrCLE4-2 dodecapeptide differs in four residues from GrCLE4-1 and in three residues from GrCLE4-3. The transgenic Gr-CLE-4-B line exhibited distinct differences in overexpression phenotypes from those of $G r$-CLE-4-C and $G r-C L E-4-D$ lines. Additionally, $G r$ $C L E-4-B$ but not $G r-C L E-4-C$ was found to completely replace $C L V 3$ activity when expressed in the stem cell domain. Together, these results reveal that $G r-C L E-4-B$ functions differently from $G r-C L E-4-C$ and $G r-C L E-4-D$, providing the first evidence to suggest that the evolution of multiple CLE motifs may be an important mechanism for generating functional diversity in CLE proteins. Arabidopsis CLE proteins that have a stronger rescue of the $\operatorname{clv} 3$ mutant phenotype require CLV1 for function, whereas those that have partial or no rescue of clv3 act independently of CLV1 (Ni and Clark 2006). According to our prediction that GrCLE1-1 functions through a receptor different from those of GrCLE4 peptides and that GrCLE4-1 and GrCLE4-3 may function through similar receptors, it might be possible that it is the GrCLE4-2 peptide that acts through CLV1 to rescue $\operatorname{clv} 3$. CLV3, and At CLE1 and At CLE6 that provided nearly complete rescue of $\operatorname{clv} 3-1$, all contain an aspartic acid residue at position 8 within their respective CLE motifs. The GrCLE4-2 peptide also contains the same residue at position 8. As suggested by Ni and Clark (2006), this aspartic acid residue might be critical for CLV3 function.

Results from our overexpression studies suggest that, like CLV3 (Rojo et al. 2002), Gr-CLE proteins may function extracellularly in planta, and nematode signal peptides are functional in Arabidopsis and can direct Gr-CLE proteins to the extracellular space for function. Intriguingly, however, Arabidopsis plants expressing individual Gr-CLE-4 proteins that lack signal peptides exhibited phenotypes similar to those expressing the corre- sponding full-length proteins. The predicted $\mathrm{N}$-terminal signal peptides found on plant CLE proteins suggest that they function in the extracellular space; therefore, it is unlikely that nematode CLE mimics can exert their function in the cytoplasm. Thus, we interpret our results to suggest that Gr-CLE proteins without their respective signal peptides may still be secreted to some extent. One possibility is that a constitutively high level of expression of Gr-CLE proteins results in some protein leakage, although constitutive overexpression of CLV3 without its signal peptide did not cause any observable phenotypes in Arabidopsis (Rojo et al. 2002). Another possibility is that the variable domain, the function of which remains unknown, plays a role in extracellular targeting of nematode CLE proteins. Future studies to monitor protein targeting will need to be undertaken to address the latter possibility.

Potato but not Arabidopsis is a host for G. rostochiensis. A short root phenotype similar to that observed in Arabidopsis was revealed when synthetic GrCLE peptides were applied exogenously to potato roots or when $G r-C L E$ genes were overexpressed in potato hairy roots, suggesting that conserved CLE signaling components that have a role in controlling root growth may exist in both Arabidopsis and potato. Several putative $C L E$ genes have been identified in the potato genome (Oelkers et al. 2008). In addition, results from in vitro and in vivo studies in potato support our hypothesis that the cognate receptor in potato that interacts with Gr-CLE-1 or its processed peptide may be different from those that interact with Gr-CLE-4-related peptides. With the completion of the potato genome, we anticipate that additional CLE genes and $C L V$ related or $R L K$ genes involved in CLE signaling will be discovered in potato. Because of the conservation of CLE signaling components observed between Arabidopsis and potato, in vitro receptor screening using Arabidopsis mutants may help identify orthologous nematode CLE receptors in potato.

It is becoming increasingly evident that nematode gland secretions play a direct role in regulating host cellular processes involved in the induction, formation, and maintenance of the syncytium (Davis et al. 2004, 2008). The discovery of the first non-plant CLE genes from $H$. glycines and associated functional characterization has led to the hypothesis that CLE proteins secreted by the nematode function as ligand mimics of plant CLE signaling peptides to directly manipulate plant developmental pathways for the dedifferentiation of root cells to form a syncytium (Mitchum et al. 2008; Wang et al. 2005). This hypothesis is further supported by recent evidence that signaling in Arabidopsis shoot and root meristems is regulated by conserved factors (Sarkar et al. 2007), including a CLV-like pathway for root meristem maintenance (Casamitjana-Martinez et al. 2003), and that both CRN and CLV2 mediate CLE signaling in Arabidopsis roots (Fiers et al. 2005; Muller et al. 2008). Consistent with this hypothesis, a recent study has demonstrated that RNAi silencing of CLE genes from $H$. glycines affects the parasitic success of the nematode (Bakhetia et al. 2007).

$G r$-CLE genes are exclusively expressed within the dorsal esophageal gland cell of parasitic stages of the nematode. Although both classes of $G r-C L E$ genes were upregulated during nematode parasitism, they showed different expression patterns during the parasitic life cycle; $G r-C L E-1$ was upregulated in the early parasitic stages with a level much lower than that of $G r$ $C L E-4$ genes and declined in later parasitic stages, whereas $G r$ $C L E-4$ genes were dramatically upregulated in early parasitic stages and remained high in later parasitic stages. The different expression patterns observed between $G r-C L E-1$ and $G r-C L E-4$ genes may suggest different functions of their gene products in plant parasitism, consistent with our prediction that Gr-CLE-1 may interact with a plant receptor different from those of Gr- 
CLE-4 proteins. Unlike $H$. glycines, which usually selects root cells with meristematic potential for syncytium formation (Endo 1964, 1991), G. rostochiensis initiates a syncytium preferentially from a fully differentiated cortical cell (Jones and Northcote 1972). It is likely that simultaneous stimulation of multiple CLE signaling pathways may be necessary for the establishment and maintenance of the syncytium. Significantly, it was recently revealed that plant CLE peptides from two functional classes act synergistically to suppress differentiation and promote auxinmediated proliferation of vascular cells in Arabidopsis (Whitford et al. 2008). Auxin has been shown to be involved in the induction and development of the syncytium (Goverse et al. 2000; Karczmarek et al. 2004). It would be interesting to determine whether the two classes of Gr-CLE genes encode for antagonistic or synergistic functions and if there is a potential interplay between auxin and nematode CLE-mediated actions in syncytium formation.

\section{MATERIALS AND METHODS}

\section{Nematode culture and inoculation.}

The potato cyst nematode ( $G$. rostochiensis) (pathotype Ro1) was propagated on greenhouse-grown susceptible potato (Solanum tuberosum cv. Katahdin) (Brodie et al. 1991) and cysts were extracted as described previously (Brodie 1996). Cysts were soaked in distilled water for 7 days and crushed to release the eggs. Infective second-stage juveniles were collected by hatching eggs in potato root diffusate (Clarke and Perry 1977) and used for inoculation on monoxenic potato root cultures to obtain nematode-infected root materials as described previously ( $\mathrm{Lu}$ et al. 2008). Root segments collected at 2 and 5 dpi were found to contain nematodes mainly at the parasitic $\mathbf{J} 2$ stage, and root segments collected at 10 and $21 \mathrm{dpi}$ were found to contain nematodes mostly at parasitic J3 and J4 stages, respectively. These infected roots were used as parasitic nematode materials for detecting $G r-C L E$ gene expression using the qRT-PCR assay described below. Mixed parasitic stages of the nematode were extracted from infected potted plants (Wang et al. 2001) and used for in situ mRNA hybridization analysis.

\section{Nucleic acid isolation.}

For mRNA isolation, frozen packed rehydrated cysts, preparasitic J2, or infected potato root segments were transferred into a Lysing Matrix D tube containing 1.4-mm ceramic spheres (Qbiogene, Carlsbad, CA, U.S.A.) and homogenized using a Mini-Beadbeater-8 Cell Disrupter (BioSpec Products, Bartlesville, OK, U.S.A.). The homogenized material was then used for mRNA extraction using the Dynabeads mRNA DIRECT Kit (Invitrogen, Carlsbad, CA, U.S.A.) following the manufacturer's instructions. mRNA (30 to $50 \mathrm{ng}$ ) was used for firststrand cDNA synthesis. For nematode genomic DNA isolation, packed preparasitic J2 (approximately $100 \mu \mathrm{l}$ ) were resuspended in $0.5 \mathrm{ml}$ of lysis buffer containing $100 \mathrm{mM} \mathrm{NaCl}, 100$ $\mathrm{mM}$ Tris- $\mathrm{HCl}, \mathrm{pH} 8.0,50 \mathrm{mM}$ EDTA, $\mathrm{pH} 8.0,1 \%$ sodium dodecyl sulfate, $1 \% \beta$-mercaptoethanol, and proteinase $\mathrm{K}$ (Invitrogen) at $100 \mu \mathrm{g} / \mathrm{ml}$ and were incubated at $65^{\circ} \mathrm{C}$ for $30 \mathrm{~min}$. Nematode DNA was extracted from the lysed mixture by phenol, phenol/chloroform (1:1), and chloroform extractions, then precipitated with ethanol.

\section{Primers used.}

Primers used for various experiments are listed in Supplementary Table 1 online.

\section{cDNA and genomic DNA cloning.}

H. glycines CLE protein sequences (Gao et al. 2003; Wang et al. 2001) were used to search the NematodeNet expressed sequence tag (EST) database using the TBLASTN program (Altschul et al. 1997), and an EST from a cDNA library of $G$. rostochiensis was identified to have similarity to the CLE motif of $H$. glycines CLE proteins. A partial sequence of the targeted gene (named $G r-C L E-1$ ) was cloned by PCR using primers of GR02145-48F and GR02145-605R and the first-strand cDNA obtained from preparasitic J2 as template. A 5' RACE procedure (Invitrogen) was then used to obtain the rest of the 5 ' untranslated region (UTR) of the gene. The full-length cDNA sequence of $G r-C L E-1$ was finally obtained by PCR using primers of CLE1-5UTRF1 and AUAP (Invitrogen). Primers of CLE1-5UTRF1 and CLE1-3UTRR2 were used for amplifying the corresponding genomic sequence of $G r-C L E-1$ from the $G$. rostochiensis genomic DNA.

Additional $G r-C L E$ genes (named $G r-C L E-4 \mathrm{~s}$ ) were obtained by PCR using primers of CLE1-ATGF and CLE1-TGAR and the first-strand cDNA obtained from preparasitic J2 or from nematode-infected root materials as template. The 3 '-end UTR of $G r-C L E-4$ genes were obtained by $3^{\prime}$ RACE using primer CLE4-359F designed according to the conserved internal regions of $G r-C L E-4$ genes and the AUAP primer (Invitrogen). The 5'-end UTR of G-CLE-4 genes were obtained by 5' RACE using primer CLE4-c265R or CLE4-c103R designed according to the conserved N-terminal regions of $G r-C L E-4$ genes and the AAP primer (Invitrogen). Full-length $G r-C L E-4$ cDNAs were then obtained by PCR using the primer pair of CLE4-5UTR1F and AUAP (Invitrogen) or the primer pair of CLE4-5UTR1F and CLE4-3UTR1R. In total, four different $G r-C L E-4$ genes (Gr-CLE-4-A, Gr-CLE-4-B, Gr-CLE-4-C, and $G r-C L E-4-D)$ were obtained. The genomic clones of $G r-C L E-4$ genes were obtained using primer pairs of CLE4-5UTR1F and CLE4-3endR2 (for $G r$-CLE-4-A), CLE4-5UTR17F and CLE43endR2 (for $G r-C L E-4-B$ ), or CLE4-5UTR1F and 31506C33UTR1R (for $G r-C L E-4-C$ and $G r-C L E-4-D$ ) designed to the corresponding cDNA sequences.

All of the amplified PCR products were cloned into the pCRII-TOPO vector (Invitrogen) and sequenced at the Cornell University Life Sciences Core Laboratories Center.

\section{In situ mRNA hybridization.}

Primers of CLE1-3UTRF2, CLE1-3UTRR2, CLE4-273F, and CLE4-349R were used to synthesize digoxigenin (DIG)labeled sense and antisense cDNA probes of $G r-C L E-1$ and Gr-CLE-4, respectively, using the PCR DIG Probe Synthesis Kit (Roche Applied Science, Indianapolis, IN, U.S.A.) by asymmetric PCR (Wang et al. 2001). Parasitic stages of the nematode were fixed, permeabilized, and used for in situ mRNA hybridization as described (De Boer et al. 1998; Wang et al. 2001). cDNA probes that hybridized within nematode specimens were detected by alkaline phosphatase-conjugated anti-DIG antibody, 5-bromo-4-chloro-3-indolyl phosphatenitroblue tetrazolium substrate staining, and compound light microscope observation.

\section{Developmental expression profiling.}

A TaqMan qRT-PCR assay was used to quantify the expression of $G r-C L E-1$ and $G r-C L E-4$ genes throughout the nematode life cycle. The $G$. rostochiensis $\beta$-actin gene (Gr-act-1) (GenBank accession no. EF437156) was used as an endogenous reference for all cDNA samples tested. Primers CLE185F and CLE1-209R and probe CLE1-c152F, which specifically hybridize to $G r-C L E-1$, were used to detect $G r-C L E-1$ transcripts. Primers CLE4-42F and CLE4-166R and probe CLE4-c120F, which specifically hybridize to $G r-C L E-4$, were used to detect $G r-C L E-4$ transcripts. Primers GrActin-c660Fb and GrActin-R2b and probe GrActin-c808F were used to detect Gr-act-1 transcripts. CLE1-c125F, GrCLE4-c120F, and 
GrActin-c808F were designed to span exon-exon junctions in the fully processed transcripts of the target genes to prevent hybridization to any potential contaminating genomic DNA in the samples. The specificity of each primer-probe pair was confirmed using corresponding cDNA and genomic DNA clones of $G r$-CLE genes as well as plant cDNA as templates. The qRT-PCR assay was carried out in an iCycler iQ RealTime PCR Detection System (Bio-Rad Laboratories, Hercules, CA, U.S.A.) as previously described ( $\mathrm{Lu}$ et al. 2008). The mRNA sample for each developmental stage was prepared from two independent experiments and used for cDNA synthesis. All qRT-PCR assays consisted of three technical replicates for each mRNA sample. Data was analyzed using the iCycler iQ Real-Time PCR Detection System Software (version 3.0a; Bio-Rad Laboratories). Gr-CLE-1 and Gr-CLE-4 expression levels were calculated using the comparative cycle threshold $\left(C_{t}\right)\left(2^{-\Delta \Delta C t}\right)$ method following a standard protocol (User Bulletin 2, ABI PRISM 7700 Sequence Detection System; Applied Biosystems, Foster City, CA, U.S.A). For each developmental stage, $2^{-\Delta \Delta \mathrm{Ct}}$ represented the amount of the target transcript that was normalized to an endogenous reference $(G r-a c t-1)$ and relative to a calibrator that had a lowest expression of the target gene at the preparasitic J2 stage. All TaqMan probes that contained a fluorescence reporter dye (6-carboxyfluorescein) and a quencher dye (6-carboxy-tetramethyl-rhodamine) at their $5^{\prime}$ and $3^{\prime}$ ends, respectively, were synthesized by Integrated DNA Technology (Coralville, IA, U.S.A).

\section{Peptide assay.}

Peptides with a purity of $>70 \%$ were synthesized (SigmaAldrich Corp., St. Louis) and dissolved in filter-sterilized 50 $\mathrm{mM}$ sodium phosphate buffer. Three Gr-CLE-1-related peptides were synthesized: GrCLE1-1-12p (12 aa, RVTPGGPD PLHN), GrCLE1-1m-12p (12 aa, RVTPGAPDPLHN, with a G-to-A conversion at position 6), and GrCLE1-1-14p (14 aa, KRVTPGGPDPLHNR). Six Gr-CLE-4-related peptides were synthesized: GrCLE4-1-12p (12 aa, RVAGAGPDPIHH), GrCLE4-1-13p (13 aa, KRVAGAGPDPIHH), GrCLE4-2-12p (12 aa, RAVPAGPDPKHH), GrCLE4-2-13p (13 aa, KRAV PAGPDPKHH), GrCLE4-3-12p (12 aa, RGAPAGPDPIHH), and GrCLE4-3-13p (13 aa, KRGAPAGPDPIHH). Positive and negative control peptides included CLV3-12p (12 aa, RTVPS GPDPLHH) and Ag-16p (16 aa, APNNHHYSSAGRQDQT) (Fiers et al. 2005). For peptide treatments, seeds of wild-type Arabidopsis (Columbia-0) and potato were surface-sterilized and plated on square plates ( 8 to 12 seeds per plate) containing the assay medium (Fiers et al. 2005) with $10 \mu \mathrm{M}$ each peptide. Assay plates were placed vertically in a growth chamber and cultured at $23^{\circ} \mathrm{C}$ for $16 \mathrm{~h}$ of light and $8 \mathrm{~h}$ of darkness. The root length was measured from the base of the hypocotyl to the tip of the primary root at several timepoints after plating. Two independent experiments were conducted.

\section{Microscopy.}

To examine root meristems, primary root tips were excised from peptide-treated Arabidopsis seedlings or from transgenic potato hairy roots and immediately mounted in water onto a glass slide. Roots were examined under an Olympus BX-50 microscope equipped with Nomarski optics and images were captured using a QImaging Retiga EXi digital CCD camera (QImaging, Surrey, BC, Canada). The root apical meristem regions of individual primary roots that covered the distance from the position around the quiescent center to the position where elongated root cells immediately follow cytoplasm-dense meristematic cells were measured microscopically. The collected data were analyzed using the MetaMorph imaging analysis software (Universal Imaging Corporation, Downingtown, PA, U.S.A.).
Transgene constructions and plant transformations.

For overexpression studies, Gr-CLE genes were subcloned into the pMD1 vector (Tai et al. 1999) under the control of the CaMV $35 S$ promoter. To generate 35S:Gr-CLE-1, 35S:Gr$C L E-1 \triangle S P$, and 35S:Gr-CLE-1 $\triangle C L E$ s constructs, primer pairs of CLE1-spF and CLE1-TGAxhoR, CLE1-nospF and CLE1TGAxhoR, and CLE1-spF and CLE1-mTAGxhoR, respectively, were used to amplify the corresponding coding regions from $G r-C L E-1$. To generate similar constructs for $G r-C L E-4$ genes, primer pairs of CLE4B1-spF and 4B1-TGAxhoR, CLE4B1nospF and 4B1-TGAxhoR, and CLE4B1-spF and 4B1mTAGxhoR were used for amplifying the corresponding sequences from $G r-C L E-4-B$ and $G r-C L E-4-C$, respectively. The same sets of primer pairs were also used for generating $G r$ $C L E-4-D$ constructs, except that the CLE4B1-spF primer was replaced with the CLE1-spF primer because the signal peptide sequence of $G r-C L E-4-D$ was identical to that of $G r-C L E-1$. Each amplified PCR product was cloned into pMD1 at the $B a m \mathrm{HI}$ and XhoI sites. The resulting constructs were transformed individually into Agrobacterium tumefaciens GV3101, and wild-type Arabidopsis (Columbia-O) plants were transformed using the A. tumefaciens-mediated floral dip method (Clough and Bent 1998).

For the complementation study, Gr-CLE genes were subcloned into pBU14 under the control of the CLV3 promoter (Brand et al. 2002). To generate the PCLV3:Gr-CLE-1 construct, primer pair CLE1-spF and CLE1-TGAxbaR was used. To generate PCLV3:Gr-CLE-4-B and PCLV3:Gr-CLE-4-C constructs, primer pair CLE4B1-spF and 4B1-TGAxbaR was used. Each amplified PCR product was cloned into pBU14 at Bam $\mathrm{HI}$ and $\mathrm{XbaI}$ sites. Arabidopsis clv3-2 mutant plants were transformed with A. tumefaciens GV3101 harboring each of the above constructs.

All transformants were selected on $0.5 \times$ MS medium containing kanamycin (Sigma-Aldrich) at $50 \mu \mathrm{g} / \mathrm{ml}$ (for the pMD1 vector) or glufosinate ammonium (Fisher, Pittsburgh) at $30 \mu \mathrm{g} / \mathrm{ml}$ (for the pBU14 vector), and transgenic Arabidopsis plants were then cultivated at $24^{\circ} \mathrm{C}$ for $16 \mathrm{~h}$ of light and $8 \mathrm{~h}$ of darkness in a growth room. For measuring the root growth rate, transgenic plants expressing individual $G r-C L E$ genes or the empty vector were first selected on kanamycincontaining medium for 5 days, then transferred to $0.5 \times \mathrm{MS}$ plates and cultured vertically at $24^{\circ} \mathrm{C}$ for $16 \mathrm{~h}$ of light and 8 $\mathrm{h}$ of darkness in a growth chamber (Percival, Perry, IA, U.S.A.).

A. rhizogenes 15834 was transformed with individual transgene constructs of interest and used for the generation of potato hairy roots as described previously (Wang et al. 2007) with some modifications. Potato stem pieces from tissue cultures were incubated with the transformed $A$. rhizogenes cell suspension for $10 \mathrm{~min}$, then transferred onto the callus induction medium containing $1 \times$ MS salts (Sigma-Aldrich), 26.7 $\mu \mathrm{M}$ glycine, $4 \mu \mathrm{M}$ nicotinic acid, $2.4 \mu \mathrm{M}$ pyridoxine HCL (Sigma-Aldrich), 1.2 $\mu \mathrm{M}$ thiamine HCL (Sigma-Aldrich), 0.5 $\mu \mathrm{M}$ folic acid, $0.2 \mu \mathrm{M}$ d-biotin (Sigma-Aldrich), $0.01 \%$ myoinositol (Acros, Morris Plains, NJ, U.S.A.), 3\% sucrose, $0.001 \%$ 6-BAP (Sigma-Aldrich), $0.002 \%$ naphthalene acetic acid (Sigma-Aldrich), and 1\% agar and cultivated for 4 days at $24^{\circ} \mathrm{C}$ without light. The infected stem pieces were then cultured on the propagation medium containing $1 \times \mathrm{MS}$ salts, $1.2 \mathrm{mM} \mathrm{NaH} \mathrm{PO}_{4}, 0.01 \%$ myo-inositol, $0.1 \%$ thiamine $\mathrm{HCl}$, $3 \%$ sucrose, $1 \%$ agar, kanamycin at $50 \mu \mathrm{g} / \mathrm{ml}$, and timentin (GlaxoSmithKline, Philadelphia) at $238 \mu \mathrm{g} / \mathrm{ml}$. Timentin was used to inhibit the growth of $A$. rhizogenes 15834 and kanamycin was added to select for transformed roots. Approximately 12 to 15 days after root emergence, $1-\mathrm{cm}$-long root tips were dissected and cultured on vertical plates containing 
the propagation medium with timentin at $119 \mu \mathrm{g} / \mathrm{ml}$ and the root growth rate was measured at different timepoints.

For detecting the expression of transgenes in transgenic Arabidopsis lines, primer pairs CLE1-c127F and CLE1-415R plus CLE4-273F and CLE4-c265R were used for detecting the expression of $G r-C L E-1$ and $G r-C L E-4$ genes, respectively. The primer pair AtGAPC-F and AtGAPC-R was used for examining the expression of the glyceraldehyde-3-phosphate dehydrogenase C subunit gene (At GAPC) (NM_111283) and the primer pair AtWUS-594F and AtWUS-903R was used for detecting WUS expression in the SAM. mRNA was extracted from the shoot apical meristems of young Arabidopsis seedlings and used for cDNA synthesis. The PCR cycling conditions were $94^{\circ} \mathrm{C}$ for $40 \mathrm{~s}$, followed by 25 (for the At GAPC gene) or 30 (for $G r-C L E$ genes) cycles of $94^{\circ} \mathrm{C}$ for $40 \mathrm{~s}, 60^{\circ} \mathrm{C}$ for $40 \mathrm{~s}, 72^{\circ} \mathrm{C}$ for $1 \mathrm{~min}$, and a final reaction of $72^{\circ} \mathrm{C}$ for 10 $\min$.

\section{Computer analyses.}

BLASTP searches against the GenBank databases at the National Center for Biotechnology Information website (Altschul et al. 1997) were performed to identify CLE protein homologues. Signal peptide analysis and protein sequence alignment were conducted using the SignalP program (Nielsen et al. 1997) and the CLUSTALX program (Thompson et al. 1997), respectively.

\section{ACKNOWLEDGMENTS}

This work was partially supported by the United States Department of Agriculture National Research Initiative grant awards 2007-35607-17790 and 2009-35302-05304 to M. G. Mitchum and X. Wang. We thank D. Thurston for maintaining nematode populations, R. Simon for providing the pBU14 vector, and R. Hussey and G. Martin for their review of the first draft of the manuscript.

\section{LITERATURE CITED}

Altschul, S. F., Madden, T. L., Schäffer, A. A., Zhang, J., Zhang, Z., Miller, W., and Lipman, D.J. 1997. Gapped BLAST and PSI-BLAST: A new generation of protein database search programs. Nucleic Acids Res. 25:3389-3402

Bakhetia, M., Urwin, P. E., and Atkinson, H. J. 2007. qPCR analysis and RNAi define pharyngeal gland cell-expressed genes of Heterodera glycines required for initial interactions with the host. Mol. Plant-Microbe Interact. 20:306-312.

Boyes, D. C., Zayed, A. M., Ascenzi, R., McCaskill, A. J., Hoffman, N. E., Davis, K. R., and Görlach, J. 2001. Growth stage-based phenotypic analysis of Arabidopsis: A model for high throughput functional genomics in plants. Plant Cell 13:1499-1510.

Brand, U., Fletcher, J. C., Hobe, M., Meyerowitz, E. M., and Simon, R. 2000. Dependence of stem cell fate in Arabidopsis on a feedback loop regulated by $C L V 3$ activity. Science 289:617-619.

Brand, U., Grunewald, M., Hobe, M., and Simon, R. 2002. Regulation of CLV3 expression by two homeobox genes in Arabidopsis. Plant Physiol. 129:565-575.

Brodie, B. B. 1996. Effect of initial nematode density on managing Globodera rostochiensis with resistant cultivars and nonhosts. J. Nematol. 28:510-519.

Brodie, B. B., Plaisted, R. L., and de Scurrah, M. M. 1991. The incorporation of resistance to Globodera pallida into Solanum tuberosum germplasm adapted to North America. Am. Potato J. 68:1-11.

Casamitjana-Martínez, E., Hofhuis, H. F., Xu, J., Liu, C.-M., Heidstra, R., and Scheres, B. 2003. Root-specific CLE19 overexpression and the soll/2 suppressors implicate a CLV-like pathway in the control of Arabidopsis root meristem maintenance. Curr. Biol. 13:1435-1441.

Cesareni, G., Panni, S., Nardelli, G., and Castagnoli, L. 2002. Can we infer peptide recognition specificity mediated by SH3 domains? FEBS (Fed. Eur. Biochem. Soc.) Lett. 513:38-44.

Clark, S. E., Running, M. P., and Meyerowitz, E. M. 1993. CLAVATA1, a regulator of meristem and flower development in Arabidopsis. Development 119:397-418.

Clark, S. E., Running, M. P., and Meyerowitz, E. M. 1995. CLAVATA3 is a specific regulator of shoot and floral meristem development affecting the same processes as CLAVATA1. Development 121:2057-2067.

Clark, S. E., Williams, R. W., and Meyerowitz, E. M. 1997. The CLAVATA1 gene encodes a putative receptor kinase that controls shoot and floral meristem size in Arabidopsis. Cell 89:575-585.

Clarke, A. J., and Perry, R. N. 1977. Hatching of cyst-nematodes. Nematologica 23:350-368.

Clough, S. J., and Bent, A. F. 1998. Floral dip: A simplified method for Agrobactrium-mediated transformation of Arabidopsis thaliana. Plant J. 16:735-743.

Cock, J. M., and McCormick, S. 2001. A large family of genes that share homology with CLAVATA3. Plant Physiol. 126:939-942.

Davis, E. L. 2009. Corrigendum: A parasitism gene from a plant-parasitic nematode with function similar to CLAVATA3/ESR (CLE) of Arabidopsis thaliana. Mol. Plant Pathol. 10:151.

Davis, E. L., Hussey, R. S., and Baum, T. J. 2004. Getting to the roots of parasitism by nematodes. Trends Parasitol. 20:134-141.

Davis, E. L., Hussey, R. S., Mitchum, M. G., and Baum, T. J. 2008. Parasitism proteins in nematode-plant interactions. Curr. Opin. Plant Biol. 11:360-366.

De Boer, J. M., Yan, Y., Smant, G., Davis, E. L., and Baum, T. J. 1998. Insitu hybridization to messenger RNA of Heterodera glycines. J. Nematol. 30:309-312.

Dropkin, V. H. 1969. Cellular responses of plant cells to nematode infections. Annu. Rev. Phytopathol. 7:101-122.

Endo, B. Y. 1964. Penetration and development of Heterodera glycines in soybean roots and related anatomical changes. Phytopathology 54:79-88.

Endo, B. Y. 1991. Ultrastructure of initial responses of susceptible and resistant soybean roots to infection by Heterodera glycines. Rev. Nematol. 14:73-94.

Ferraro, E., Peluso, D., Via, A., Ausiello, G., and Helmer-Citterich, M. 2007. SH3-Hunter: Discovery of SH3 domain interaction sites in proteins. Nucleic Acids Res. 35:W451-454.

Fiers, M., Hause, G., Boutilier, K., Casamitjana-Martinez, E., Weijers, D., Offringa, R., van der Geest, L., van Lookeren Campagne, M., and Liu, C. M. 2004. Mis-expression of the CLV3/ESR-like gene CLE19 in Arabidopsis leads to a consumption of root meristem. Gene 327:37-49.

Fiers, M., Golemiec, E., Xu, J., van der Geest, L., Heidstra, R., Stiekema, W., and Liu, C.-M. 2005. The 14-amino acid CLV3, CLE19, and CLE40 peptides trigger consumption of the root meristem in Arabidopsis through a CLAVATA2-dependent pathway. Plant Cell 17:2542-2553.

Fiers, M., Golemiec, E., van der Schors, R., van der Geest, L., Li, K. W., Stiekema, W. J., and Liu, C.-M. 2006. The CLAVATA3/ESR motif of CLAVATA3 is functionally independent from the nonconserved flanking sequences. Plant Physiol. 141:1284-1292.

Fletcher, J. C., Brand, U., Running, M. P., Simon, R., and Meyerowitz, E. M. 1999. Signaling of cell fate decisions by CLAVATA3 in Arabidopsis shoot meristems. Science 283:1911-1914.

Gao, B., Allen, R., Maier, T., Davis, E. L., Baum, T. J., and Hussey, R. S. 2003. The parasitome of the phytonematode Heterodera glycines. Mol. Plant-Microbe Interact. 16:720-726.

Goverse, A., Overmars, H., Engelbertink, J., Schots, A., Bakker, J., and Helder, J. 2000. Both induction and morphogenesis of cyst nematode feeding cells are mediated by auxin. Mol. Plant-Microbe Interact. 13:1121-1129.

Hirakawa, Y., Shinohara, H., Kondo, Y., Inoue, A., Nakanomyo, I., Ogawa, M., Sawa, S., Ohashi-Ito, K., Matsubayashi, Y., and Fukuda, H. 2008. Non-cell-autonomous control of vascular stem cell fate by a CLE peptide/receptor system. Proc. Natl. Acad. Sci. U.S.A. 105:15208-15213.

Hobe, M., Muller, R., Grunewald, M., Brand, U., and Simon, R. 2003. Loss of CLE40, a protein functionally equivalent to the stem cell restricting signal CLV3, enhances root waving in Arabidopsis. Dev. Genes Evol. 213:371-381.

Hou, T., Chen, K., McLaughlin, W. A., Lu, B., and Wang, W. 2006. Computational analysis and prediction of the binding motif and protein interacting partners of the Abl SH3 domain. PLoS Comput. Biol. 2:e1. Published online.

Hussey, R. S. 1989. Disease-inducing secretions of plant parasitic nematodes. Annu. Rev. Phytopathol. 27:123-141.

Hussey, R. S., and Grundler, F. M. W. 1998. Nematode parasitism of plants. Pages 213-243 in: Physiology and Biochemistry of Free-Living and Plant-Parasitic Nematodes. R. N. Perry and D. J. Wright, eds. CAB International Press, Oxford.

Ito, Y., Nakanomyo, I., Motose, H., Iwamoto, K., Sawa, S., Dohmae, N., and Fukuda, H. 2006. Dodeca-CLE peptides as suppressors of plant stem cell differentiation. Science 313:842-845.

Jeong, S., Trotochaud, A. E., and Clark, S. E. 1999. The Arabidopsis CLAVATA2 gene encodes a receptor-like protein required for the stability of the CLAVATA1 receptor-like kinase. Plant Cell 11:1925-1933.

Jones, M. G. K. 1981. Host cell responses to endoparasitic nematode attack: Structure and function of giant cells and syncytia. Ann. Appl. Biol 
97:353-372.

Jones, M. G. K., and Northcote, D. H. 1972. Nematode induced syncytium - a multinucleate transfer cell. J. Cell Sci. 10:789-809.

Karczmarek, A., Overmars, H., Helder, J., and Goverse, A. 2004. Feeding cell development by cyst and root-knot nematodes involves a similar early, local and transient activation of a specific auxin-inducible promoter element. Mol. Plant Pathol. 5:343-346.

Kayes, J. M., and Clark, S. E. 1998. CLAVATA2, a regulator of meristem and organ development in Arabidopsis. Development 125:3843-3851.

Kinoshita, A., Nakamura, Y., Sasaki, E., Kyozuka, J., Fukuda, H., and Sawa, S. 2007. Gain-of-function phenotypes of chemically synthetic CLAVATA3/ESR-related (CLE) peptides in Arabidopsis thaliana and Oryza sativa. Plant Cell Physiol. 48:1821-1825.

Kondo, T., Sawa, S., Kinoshita, A., Mizuno, S., Kakimoto, T., Fukuda, H., and Sakagami, Y. 2006. A plant peptide encoded by CLV3 identified by in situ MALDI-TOF MS analysis. Science 313:845-848.

Laux, T., Mayer, K. F. X., Berger, J., and Jürgens, G. 1996. The WUSCHEL gene is required for shoot and floral meristem integrity in Arabidopsis. Development 122:87-96.

Lu, S.-W., Tian, D., Borchardt-Wier, H. B., and Wang, X. 2008. Alternative splicing: A novel mechanism of regulation identified in the chorismate mutase gene of the potato cyst nematode Globodera rostochiensis. Mol. Biochem. Parasitol. 162:1-15.

Mayer, K. F. X., Schoof, H., Haecker, A., Lenhard, M., Jurgens, G., and Laux, T. 1998. Role of WUSCHEL in regulating stem cell fate in the Arabidopsis shoot meristem. Cell 95:805-815.

Mitchum, M. G., Wang, X., and Davis, E. L. 2008. Diverse and conserved roles of CLE peptides. Curr. Opin. Plant Biol. 11:75-81.

Muller, R., Bleckmann, A., and Simon, R. 2008. The receptor kinase CORYNE of Arabidopsis transmits the stem cell-limiting signal CLAVATA3 independently of CLAVATA1. Plant Cell 20:934-946.

Ni, J., and Clark, S. E. 2006. Evidence for functional conservation, sufficiency, and proteolytic processing of the CLAVATA3 CLE domain. Plant Physiol. 140:726-733.

Nielsen, H., Engelbrecht, J., Brunak, S., and von Heijne, G. 1997. Identification of prokaryotic and eukaryotic signal peptides and prediction of their cleavage sites. Protein Eng. 10:1-6.

Oelkers, K., Goffard, N., Weiller, G. F., Gresshoff, P. M., Mathesius, U., and Frickey, T. 2008. Bioinformatic analysis of the CLE signaling peptide family. BMC Plant Biol. 8:1.

Ogawa, M., Shinohara, H., Sakagami, Y., and Matsubayashi, Y. 2008. Arabidopsis CLV3 peptide directly binds CLV1 ectodomain. Science 319:294.

Olsen, A. N., and Skriver, K. 2003. Ligand mimicry? Plant-parasitic nematode polypeptide with similarity to CLAVATA3. Trends Plant Sci. 8:5557.

Rojo, E., Sharma, V. K., Kovaleva, V., Raikhel, N. V., and Fletcher, J. C. 2002. CLV3 is localized to the extracellular space, where it activates the Arabidopsis CLAVATA stem cell signaling pathway. Plant Cell 14:969977.
Sarkar, A. K., Luijten, M., Miyashima, S., Lenhard, M., Hashimoto, T., Nakajima, K., Scheres, B., Heidstra, R., and Laux, T. 2007. Conserved factors regulate signaling in Arabidopsis thaliana shoot and root stem cell organizers. Nature 446:811-814.

Schoof, H., Lenhard, M., Haecker, A., Mayer, K. F. X., Jurgens, G., and Laux, T. 2000. The stem cell population of Arabidopsis shoot meristem is maintained by a regulatory loop between the CLAVATA and WUSCHEL genes. Cell 100:635-644.

Strabala, T. J., O’Donnell P. J., Smit, A.-M., Ampomah-Dwamena, C., Martin, E. J., Netzler, N., Nieuwenhuizen, N. J., Quinn, B. D., Foote, H. C. C., and Hudson, K. R. 2006. Gain-of-function phenotypes of many CLAVATA3/ESR genes, including four new family members, correlate with tandem variations in the conserved CLAVATA3/ESR domain. Plant Physiol. 140:1331-1344.

Tai, T. H., Dahlbeck, D., Clark, E. T., Gajiwala, P., Pasion, R., Whalen, M C., Stall, R. E., and Staskawicz, B. J. 1999. Expression of the Bs2 pepper gene confers resistance to bacterial spot disease in tomato. Proc. Natl. Acad. Sci. U.S.A. 96:14153-14158.

Thompson, J. D., Gibson, T. J., Plewniak, F., Jeanmougin, F., and Higgins, D. G. 1997. The CLUSTAL X windows interface: Flexible strategies for multiple sequence alignment aided by quality analysis tools. Nucleic Acids Res. 25:4876-4882.

Wang, X., Allen, R., Ding, X., Goellner, M., Maier, T., de Boer, J. M. Baum, T. J., Hussey, R. S., and Davis, E. L. 2001. Signal peptide-selection of cDNA cloned directly from the esophageal gland cells of the soybean cyst nematode Heterodera glycines. Mol. Plant-Microbe Interact. 14:536-544.

Wang, X., Mitchum, M. G., Gao, B., Li, C., Diab, H., Baum, T. J., Hussey, R. S., and Davis, E. L. 2005. A parasitism gene from a plant-parasitic nematode with function similar to CLAVATA3/ESR (CLE) of Arabidopsis thaliana. Mol. Plant Pathol. 6:187-191.

Wang, X., Replogle, A., Davis, E. L., and Mitchum, M. G. 2007. The tobacco $\mathrm{Cel} 7$ gene promoter is auxin-responsive and locally induced in nematode feeding sites of heterologous plants. Mol. Plant Pathol. 8:423-436.

Whitford, R., Fernandez, A., De Groodt, R., Ortega, E., and Hilson, P. 2008. Plant CLE peptides from two distinct functional classes synergistically induce division of vascular cells. Proc. Natl. Acad. Sci. U.S.A. 105:18625-18630.

Zarrinpar, A., Bhattacharyya, R. P., and Lim, W. A. 2003. The structure and function of proline recognition domains. Sci. STKE 2003:re8. Published online.

\section{AUTHOR-RECOMMENDED INTERNET RESOURCES}

NematodeNet database: www.nematode.net

SH3-Hunter: cbm.bio.uniroma2.it/SH3-Hunter

National Center for Biotechnology Information Blast database: www.ncbi.nlm.nih.gov/BLAST 